[American Journal of Science, Vol. 308, October, 2008, P. 905-941, DOI 10.2475/08.2008.02]

\title{
THE SURFACE CHEMISTRY OF DIVALENT METAL CARBONATE MINERALS; A CRITICAL ASSESSMENT OF SURFACE CHARGE AND POTENTIAL DATA USING THE CHARGE DISTRIBUTION MULTI-SITE ION COMPLEXATION MODEL
}

\author{
MARIËTTE WOLTHERS $* * *,+$, LAURENT CHARLET*, and \\ PHILIPPE VAN CAPPELLEN**
}

\begin{abstract}
The Charge Distribution MUltiSite Ion Complexation or CD-MUSIC modeling approach is used to describe the chemical structure of carbonate mineralaqueous solution interfaces. The new model extends existing surface complexation models of carbonate minerals, by including atomic scale information on the surface lattice and the adsorbed water layer. In principle, the model can account for variable proportions of face, edge and kink sites exposed at the mineral surface, and for the formation of inner- and outer-sphere surface complexes. The model is used to simulate the development of surface charges and surface potentials on divalent carbonate minerals as a function of the aqueous solution composition. A comparison of experimental data and model output indicates that the large variability in the observed $\mathrm{pH}$ trends of the surface potential for calcite may in part reflect variable degrees of thermodynamic disequilibrium between mineral, solution and, when present, gas phase during the experiments. Sample preparation and non-stoichiometric surfaces may introduce further artifacts that complicate the interpretation of electrokinetic and surface titration measurements carried out with carbonate mineral suspensions. The experimental artifacts, together with the high sensitivity of the model toward parameters describing hydrogen bridging and bond lengths at the mineralwater interface, currently limit the predictive application of the proposed CD-MUSIC model. The results of this study emphasize the need for internally consistent experimental data sets obtained with well-characterized mineral surfaces and in situ aqueous solution compositions (that is, determined during the charge or potential measurements), as well as for further molecular dynamic simulations of the carbonate mineral-water interface to better constrain the bond lengths and the number plus valence contribution of hydrogen bridges associated with different structural surface sites.
\end{abstract}

INTRODUCTION

Carbonate minerals play an important role in regulating the chemistry of aquatic environments, including the oceans, aquifers, hydrothermal systems, soils and sediments. Through mineral surface processes such as dissolution, precipitation and sorption, carbonate minerals affect the biogeochemical cycles of not only the constituent elements of carbonates, such as $\mathrm{Ca}, \mathrm{Mg}, \mathrm{Fe}$ and $\mathrm{C}$, but also $\mathrm{H}, \mathrm{P}$ and trace elements (for example, Morse and Mackenzie, 1990; Archer and Maier-Reimer, 1994; Rimstidt and others, 1998; Mackenzie, 2003; Martin-Garin and others, 2003; Jahnke and Jahnke, 2004; Morse and others, 2006).

The surface chemistry of divalent metal carbonate minerals has received ample attention. The macroscopic properties of carbonate mineral surfaces were initially studied using electrokinetic measurements and limited residence-time potentiometric titrations (see review in table 1 and compilation of calcite electrokinetic measurements in fig. 1). Since the 1990's, the application of sophisticated surface imaging (Hillner and others, 1992; Rachlin and others, 1992; Ohnesorge and Binnig, 1993; Gratz and France

* Environmental Geochemistry Group, LGIT, University Grenoble I, BP 53, 8041, Grenoble Cedex,

** Department of Earth Sciences-Geochemistry, Faculty of Geosciences, Utrecht University, P.O. Box 80021, 3508 TA Utrecht, The Netherlands

† Corresponding author: wolthers@geo.uu.nl 


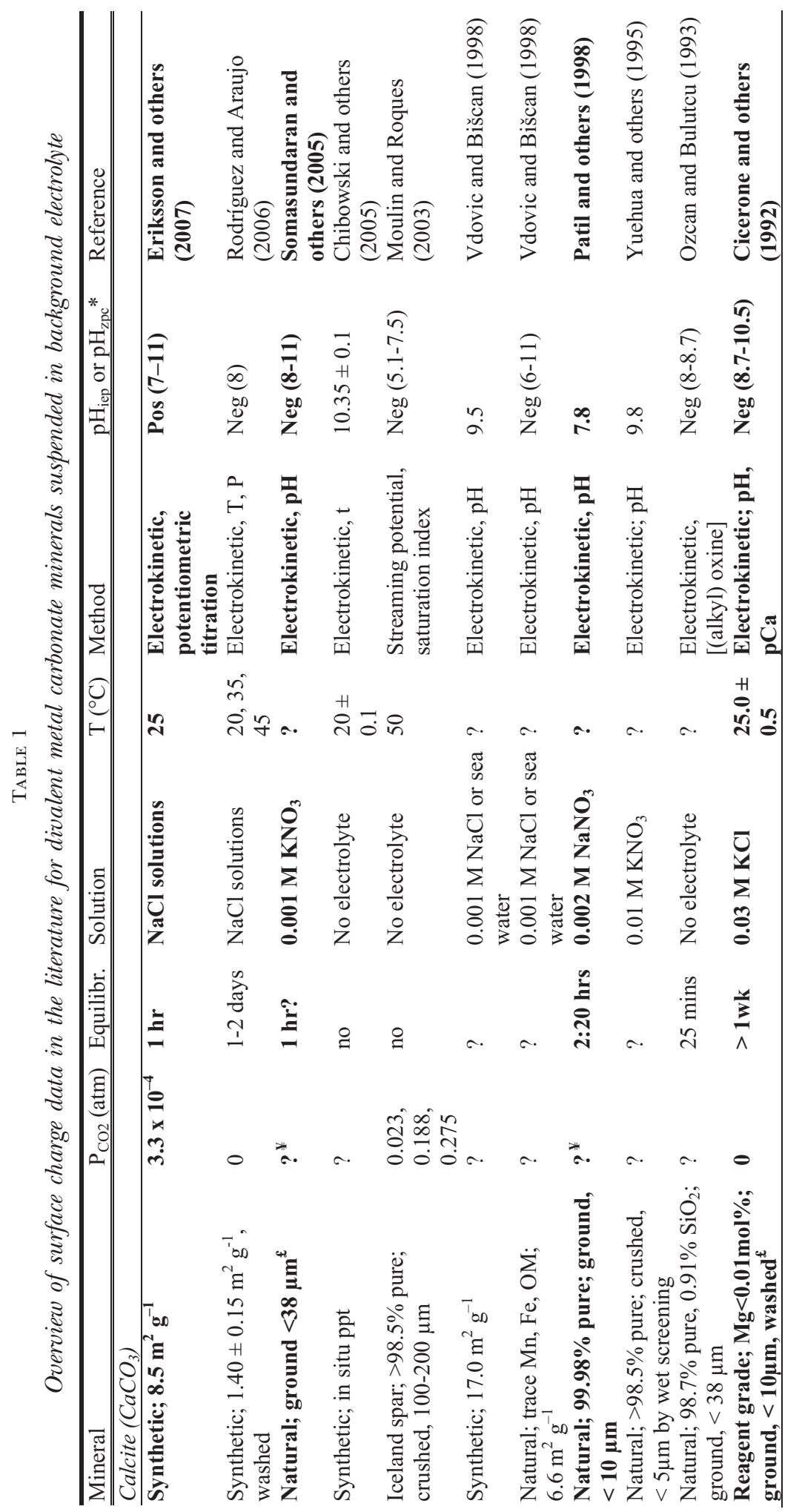


metal carbonate minerals; a critical assessment of surface charge and potential data 907

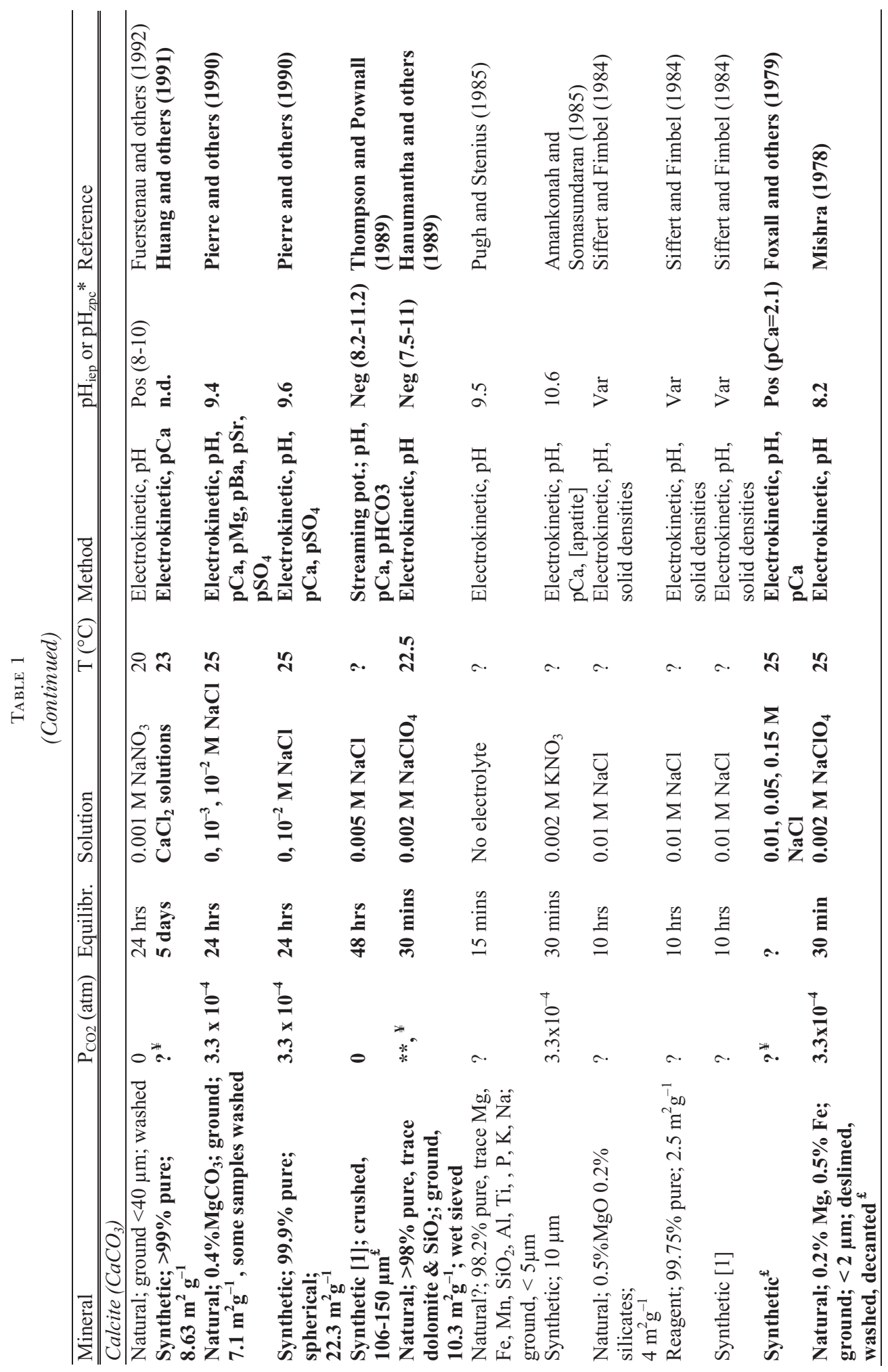




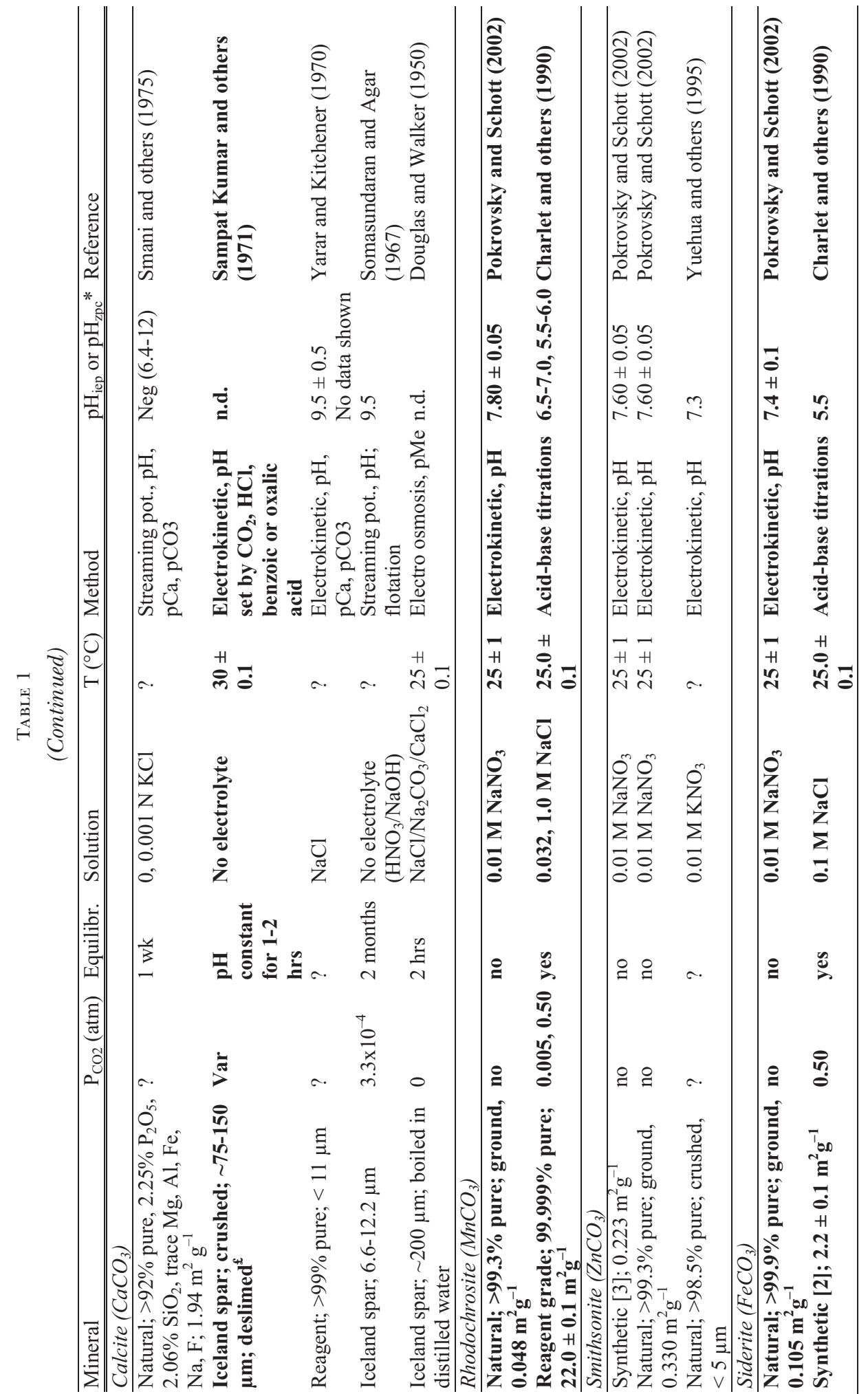


metal carbonate minerals; a critical assessment of surface charge and potential data 909

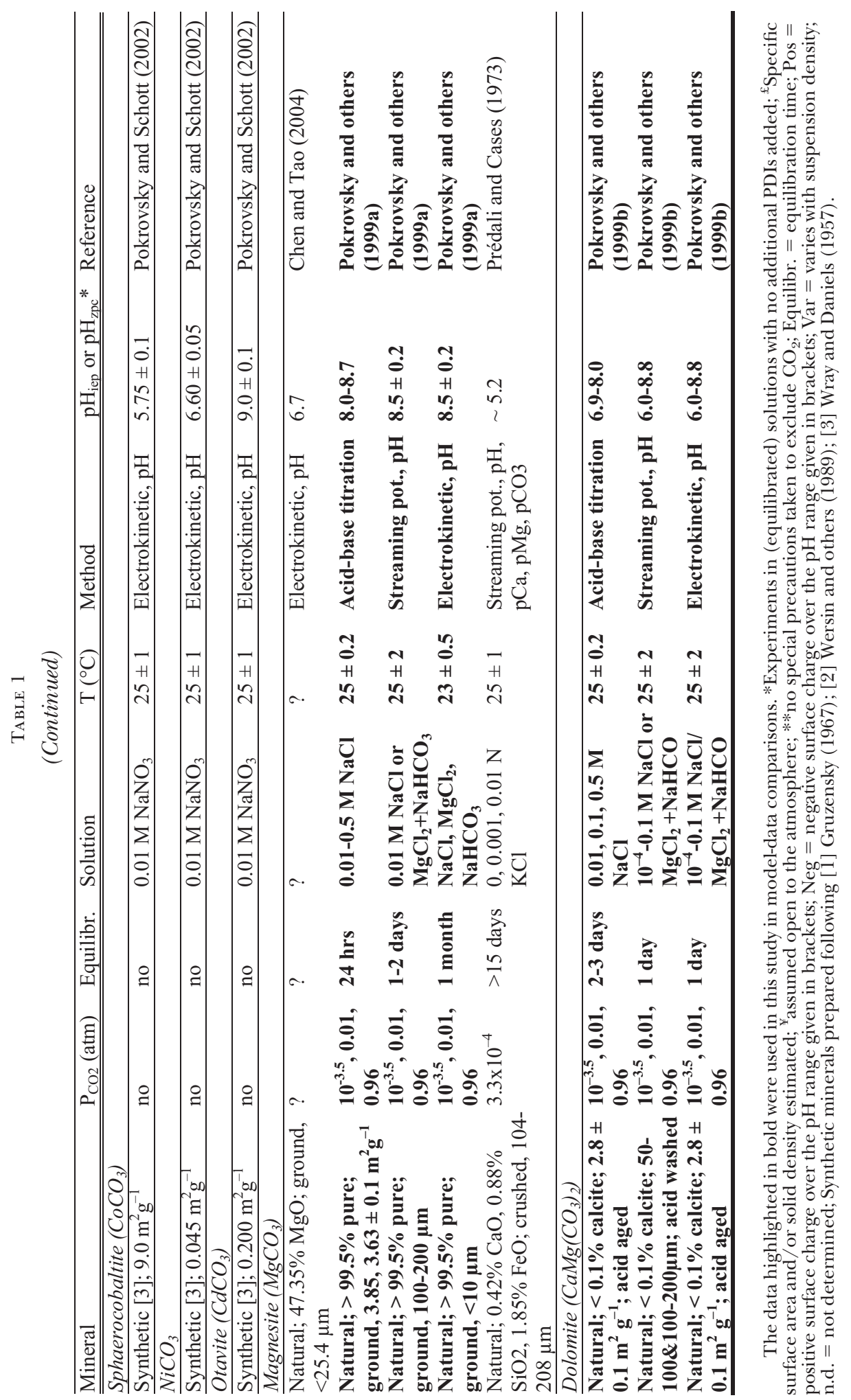




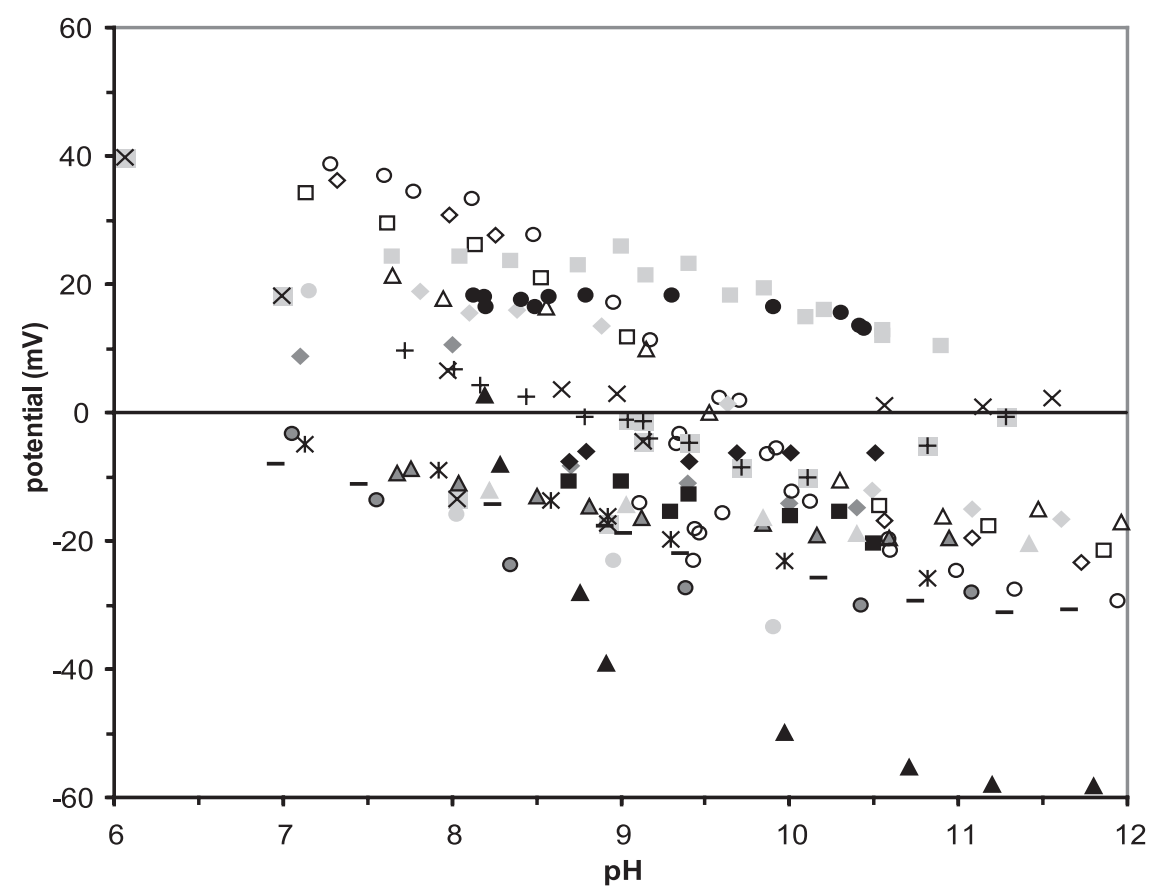

Fig. 1. Selected literature streaming and $\zeta$-potential data for calcite for washed (closed black and dark gray symbols) and unwashed (other symbols) from Sampat Kumar and others $(1971 ; \mathbf{X})$, Mishra $(1978 ; \diamond)$, Hanumantha and others $(1989 ; \triangle)$, Thompson and Pownall $(1989 ;-, \mathcal{X}, \mathbf{X},+, \pm)$, Pierre and others $(1990 ; \boldsymbol{\Delta}, \diamond, \square, \diamond, \triangle, \bigcirc)$, Cicerone and others $(1992 ; \mathbf{\square}, \diamond, \bullet)$, Patil and others (1998; $\odot$ ), Somasundaran and others $(2005 ; \Delta)$, and Eriksson and others $(2007 ;-)$. For more information on the data, see table 1 and captions figures 5 and 6 .

others, 1993; Stipp and others, 1996; Liang and Baer, 1997; Jordan and Rammensee, 1998; Teng and others, 1999, 2000; De Guidici, 2002; Duckworth and Martin, 2003; Na and others, 2007) and spectroscopic methods (Stipp and Hochella, 1991; Chiarello and others, 1993; Stipp and others, 1994; Fenter and others, 2000; Pokrovsky and others, 2000; Geissbühler and others, 2004), plus the development of molecular models for (hydrated) carbonate mineral surfaces (De Leeuw and Parker, 1997, 1998; Titiloye and others, 1998; Wright and others, 2001, 2002; Lasaga and Lüttge, 2001; Cygan and others, 2002; Rohl and others, 2003; Kerisit and Parker, 2004) have significantly advanced our comprehension of the microscopic structure and reactivity of carbonate mineral-aqueous solution interfaces.

Surface complexation models (SCMs) provide a bridge between the macro-scale surface charging and sorption properties of carbonate minerals and the chemical structure of surface sites derived from spectroscopic information. The existing two-site SCM represents the hydrated carbonate mineral surface as an array of cation $\left(\equiv \mathrm{CaOH}^{\circ}\right)$ and anion sites $\left(\equiv \mathrm{CO}_{3} \mathrm{H}^{\circ}\right)$ (Van Cappellen and others, 1993; Pokrovsky and others, 1999a, 1999b, 2000; Pokrovsky and Schott, 1999, 2002; see review below) and uses the constant capacitance model to describe the electric double layer. However, as Van Cappellen and others (1993) remarked, this model corresponds to an idealized, averaged representation of the mineral-solution interface. The model does not take into account the diversity of micro-topographical sites exposed at real mineral surfaces, such as face, step and kink sites. As a logical next step, the Charge Distribution MUltiSite Ion Complexation (CD-MUSIC) modeling approach allows one to include 
crystallographically distinct surface coordination sites. The application of the CDMUSIC approach to carbonate mineral surfaces is the subject of this paper.

The MUSIC model approach uses the valence bond theory to describe the charging of mineral surfaces (Hiemstra and others, 1989a, 1989b). Valence bond theory, a refinement of Pauling's valence bond concept, has been used successfully to interpret the bulk structures of crystals. The theory can, however, also be applied to crystal surfaces. The MUSIC model was initially developed (Hiemstra and others, 1989a, 1989b) and refined to the CD-MUSIC model (Hiemstra and others, 1996; Hiemstra and Van Riemsdijk, 1996) for simple metal (hydr)oxides. Recently, the CD-MUSIC model has also been applied successfully to describe the surface charging of montmorillonite in aqueous solution (Tournassat and others, 2004). Here, it is used to theoretically describe the dependence of the surface charging of divalent metal carbonate minerals on $\mathrm{pH}$, the aqueous metal concentration and $P_{\mathrm{CO} 2}$.

In order to apply the CD-MUSIC model, it is necessary to define the microscopic/ atomistic surface structure. In other words, one must specify which crystal faces are exposed and which types of sites are present at the mineral surface. This is a major difference between the existing SCM of the carbonate-water interface and the CDMUSIC model. Explicitly distinguishing face, edge and corner sites opens new avenues for the interpretation and modeling of adsorption reactions, incorporation of foreign elements, and carbonate mineral growth and dissolution (step edge movement). After reviewing the available structural information for carbonate mineral surfaces, and deriving this information from crystallography if necessary, the charge and proton affinity for each type of site are calculated with the CD-MUSIC model. The resulting proton affinity constants are then compared to those in the existing two-site SCM. The two modeling steps, the derivation of the site types and the calculation of the charges and proton affinities, are illustrated in detail for calcite. Because the dissolved mineral constituents, that is, the divalent metal cations and carbonate anions, are potential determining ions (PDIs), their adsorption onto the mineral surface is also addressed within the CD-MUSIC framework. The CD-MUSIC model is subsequently used to systematically analyze the available electrokinetic data for calcite and constrain the possible causes of the large variability in the observed $\mathrm{pH}$ trends. Finally, surface charges and surface potentials for a number of other divalent metal carbonates under variable solution conditions are simulated with the model.

\section{BACKGROUND}

\section{Existing Surface Complexation Models}

The first SCM model to quantitatively describe the acid-base and electrical charging properties of carbonate mineral-aqueous solution interfaces was developed by Van Cappellen and others (1993) (table 2). They based their model on the work of Stipp and Hochella (1991), who presented X-ray photoelectron spectroscopic (XPS) measurements supporting the existence of hydrated calcium, $\equiv \mathrm{CaOH}^{\circ}$, and carbonate, $\equiv \mathrm{CO}_{3} \mathrm{H}^{\circ}$, sites (where $\equiv$ symbolizes the mineral surface lattice) on fresh calcite surfaces exposed to water. The model further assumed that the density of hydrated surface sites reflects the density and stoichiometry of lattice sites along cleavage and growth planes. The formal description of the chemical structure of the carbonate mineral-water interface relied on the analogy between surface and solution complexation reactions, as described in surface complexation theory (for example, Schindler and Stumm, 1987). The surface complex formation constants were fitted to the $\mathrm{pH}$ dependent surface charge data for rhodochrosite and siderite obtained from potentiometric titrations (Charlet and others, 1990), and the point of zero charge for calcite measured by electrophoresis by Mishra (1978). The model, even without fitting to experimental data, was able to reproduce essential features of the surface chemistry of 
912 M. Wolthers, L. Charlet, and P. Van Cappellen-The surface chemistry of divalent

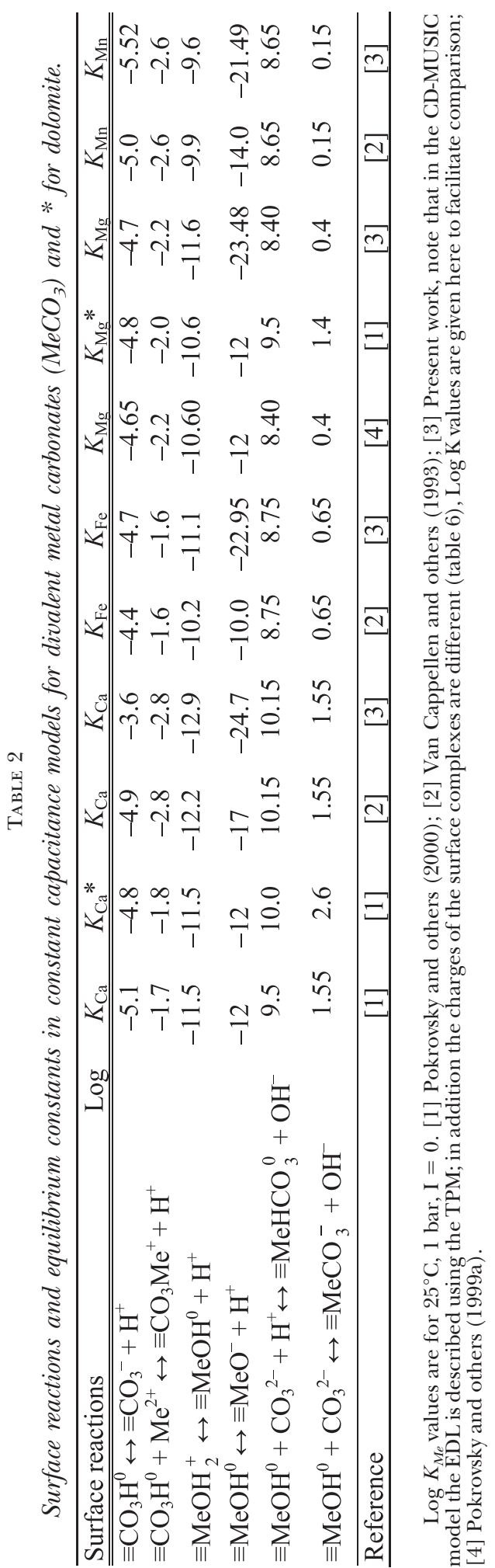


carbonate minerals in aqueous solutions, especially (i) the dependence of the zero point of charge $\left(\mathrm{pH}_{\mathrm{ZPC}}\right)$ on $P_{\mathrm{CO}_{2}}$, and (ii) the relative insensitivity of the surface charge $\mathrm{pH}$ dependence towards ionic strength. Moreover, the model explained the $\mathrm{pH}$ dependence of the dissolution kinetics of calcite in terms of variations in surface speciation.

Since then, Pokrovsky and co-workers extended and refined the model by considering additional divalent metal carbonates (table 2; for an overview of all divalent metal carbonates included, see Pokrovsky and Schott, 2002). Like Van Cappellen and others (1993), they assumed that the density of hydrated surface sites reflects the density and stoichiometry of lattice sites along the cleavage and growth planes. They showed that the stability constants of the hydrolysis reactions of the metal surface sites correlate linearly with metal hydration constants in solution for a broad range of metals. However, no clear correlation was observed between stability constants of aqueous metal carbonate complexes and carbonate adsorbed on metal surface sites. Possibly, this points to important structural differences between carbonate-bearing surface and aqueous complexes (Pokrovsky and Schott, 2002). The SCM was capable of reproducing the acid-base titration data of magnesite (Pokrovsky and others, 1999a), dolomite (Pokrovsky and others, 1999b), and the isoelectric points of all analyzed divalent metal carbonates (Pokrovsky and Schott, 2002).

For rhodochrosite and siderite, surface charges derived from potentiometric titrations (Charlet and others, 1990) were shown to be consistent with electrokinetic measurements (Pokrovsky and others, 1999a, 1999b, 2000; Pokrovsky and Schott, 2002). Furthermore, for the surfaces of calcite and dolomite, the predicted variations in surface speciation with $\mathrm{pH}$ were supported by infrared and X-ray reflectivity spectroscopy (Stipp and Hochella, 1991; Stipp and others, 1994; Chiarello and Sturchio, 1995; Pokrovsky and others, 2000). As mentioned above, XPS evidence for the presence of $\equiv \mathrm{CaOH}^{\circ}$ and $\equiv \mathrm{CO}_{3} \mathrm{H}^{\circ}$ at the surface of hydrated calcite crystals (Stipp and Hochella, 1991) formed the basis for the development of the first carbonate SCM.

X-ray reflectivity (Chiarello and Sturchio, 1995) and XPS (Stipp and Hochella, 1991) data for calcite have shown that the spacing and long range ordering of the near-surface lattice are statistically identical to those of the bulk calcite lattice. These observations validate the assumption that the density of hydrated surface sites reflects the density and stoichiometry of lattice sites along cleavage and growth planes. Infrared (IR) spectroscopy of the (semi-) hydrated surfaces of calcite and dolomite showed, with $\mathrm{pH}$ decreasing from $\sim 10$ to $\sim 5$, a simultaneous increase in the integrated intensities of spectral bands assigned to the surface hydroxyl groups and a decrease in integrated intensity of the spectral bands assigned to the surface carbonate groups, a trend predicted by surface complexation modeling (Pokrovsky and others, 2000). Also, the density of surface hydroxyl groups plus the ratio of hydroxyl to carbonate surface groups were in agreement with the model predicted values for calcite and dolomite surfaces (Pokrovsky and others, 2000).

So far, however, the vast body of measured calcite surface potentials has not been used to calibrate or test the existing Surface Complexation Models of the carbonateaqueous solution interface.

\section{Carbonate Mineral-Water Interface}

The build-up of charge at carbonate mineral surfaces, as deduced from acid-base titrations (Charlet and others, 1990; Pokrovsky and others, 1999a), is $\sim 100$ times higher per unit surface area than for oxide minerals. Within the framework of the constant capacitance model (CCM), which has been used by Van Cappellen and others (1993) and Pokrovsky and co-workers to describe the charge-potential relationship in the electric double layer (EDL), this requires capacitances that are one to two orders of magnitude higher for carbonate minerals than for iron oxides. Van Cappellen and 


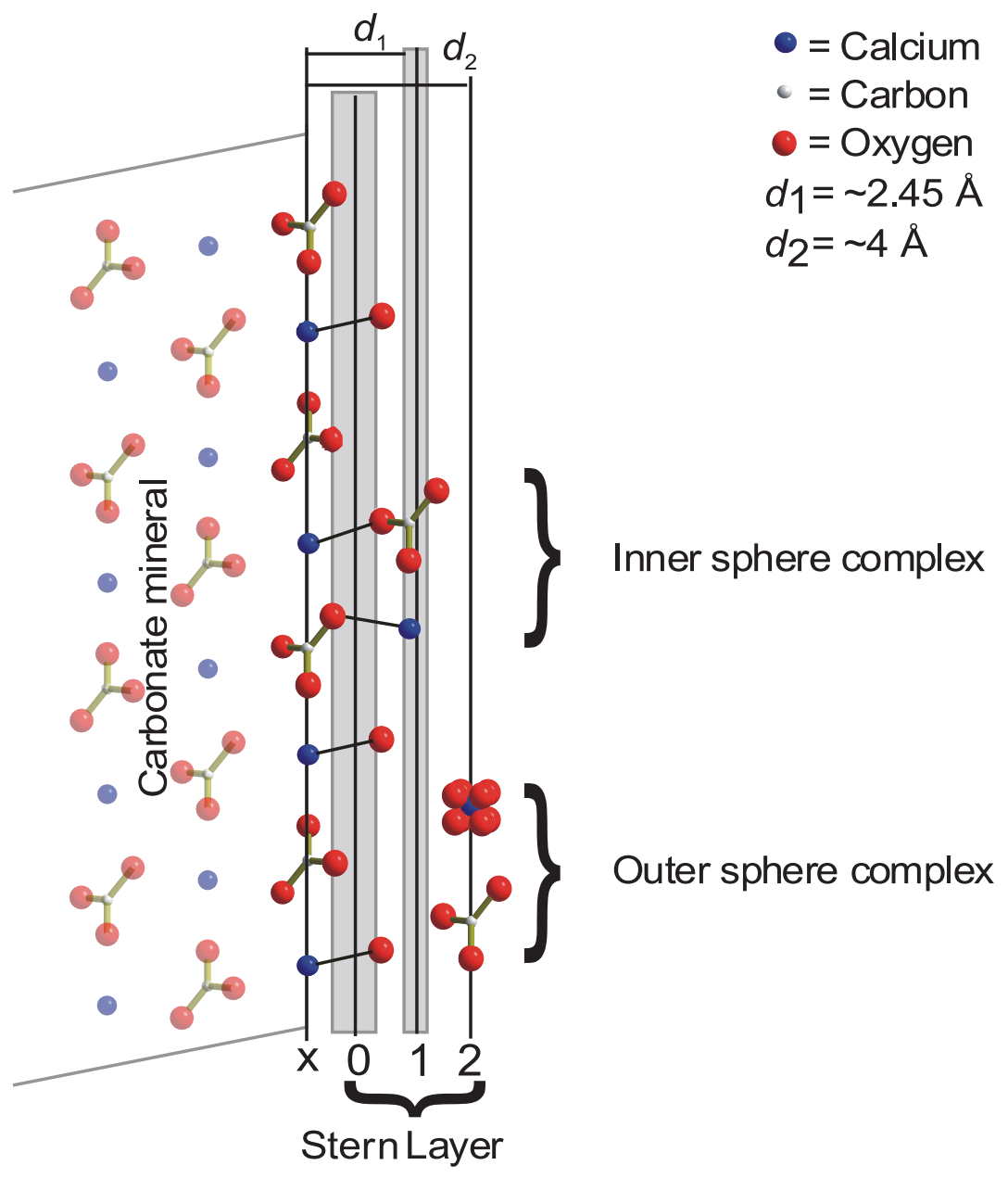

Fig. 2. Sketch of the location of the plane of crystal truncation $(\mathrm{x})$ and the three planes that together describe the Stern layer: the 0-plane, cutting through the oxygen atoms in surface and adsorbed carbonate groups and hydroxylated surface metal ions; the 1-plane for inner sphere complexes; and the 2-plane for outer sphere complexation. Atoms are not to scale.

others (1993) interpreted this observation to imply a thin, highly structured and hence non-diffuse EDL capable of accommodating high charge densities. In order for the Stern-Layer to have a physically reasonable thickness $(\sim 1 \AA)$, it can be inferred from the high capacitances that the dielectric constant of the interfacial water must be low, close to the value for fully structured water (Bockris and Khan, 1993).

Both theoretical and experimental studies provide evidence for a distinct layering of the water at the calcite-water interface. Geissbühler and others (2004) presented X-ray reflectivity data showing that the water layer adsorbed to the (1014) face of calcite is laterally ordered. They observed two adsorbed water layers at different heights from the surface plane (defined as the outer layer of lattice Ca atoms; fig. 2), the first one at $2.3 \pm 0.1 \AA$, the second one, with more weakly absorbed water molecules, at $3.45 \pm 0.2 \AA$. Molecular dynamics simulations of a $\sim 30 \AA$-thick water layer separating equivalent (1014) faces of calcite (Kerisit and others, 2003; Kerisit and Parker, 2004) are in general agreement with the X-ray reflectivity results. The simu- 
lated surface hydration layer was observed to consist of two different layers of water molecules, at $2.2 \AA$ and $3.2 \AA$ above the surface calcium ions. The structure of the water was significantly different from bulk water for up to $\sim 10 \AA$ away from the surface.

Strong specific interaction between counter-ions and the mineral surface may help explain the non-diffuse nature of the EDL of carbonate minerals, as suggested by Pokrovsky and Schott (2002). The weak dependency of the surface charge of metal carbonates on ionic strength, but its strong dependency on the aqueous concentrations of the lattice ions, supports this view. Thus, in contrast to metal oxides, carbonate mineral dissolution releases counter-ions that develop specific interactions with the solid surface, causing an intrinsic difference in the chemical structure of the EDL for these two types of minerals (Pokrovsky and others, 1999a).

Surface complexation models explicitly take into account specific interactions between aqueous species and mineral surface sites. Pokrovsky and co-workers treated the sorption of the constitutive divalent cations, Me(II), to carbonate surface groups as outer-sphere complexation with some water molecules between the surface site and the adsorbed hydrated Me(II) (Pokrovsky and others, 2000). Molecular dynamic simulations of the calcite surface have indicated that $\mathrm{Ca}$ (II) adsorbed as an outer sphere complex has an average coordination of 8.2 water molecules, while $\mathrm{Ca}$ (II) adsorbed as an inner sphere complex has an average coordination to 6.4 water molecules (Kerisit and Parker, 2004). Dehydration of the adsorbed hydrated Me(II) has been suggested to be the rate limiting step in the (co) precipitation of various metal carbonates (Wersin and others, 1989; Pokrovsky and Schott, 2002).

$\mathrm{X}$-ray and IR spectroscopic measurements point to the presence of $\equiv \mathrm{CaOH}^{\circ}$ and $\equiv \mathrm{CO}_{3} \mathrm{H}^{\circ}$ sites at the surface of hydrated calcite crystals (Stipp and Hochella, 1991; Stipp and others, 1994; Pokrovsky and others, 2000), implying sorption of hydroxyl ions onto the calcium surface sites and protonation of the surface carbonate groups. However, as hydrogen is not directly detected by these techniques (Stipp and Hochella, 1991; Pokrovsky, personal communication), $\equiv \mathrm{CaOH}^{\circ}$ is indistinguishable from $\equiv \mathrm{CaOH}_{2}^{+}$. Thus, strictly speaking, these techniques cannot distinguish a hydroxyl ion adsorbed to a surface calcium site from a water molecule adsorbed to a surface calcium. X-ray reflectivity measurements suggest that water molecules complete the coordination shells of the surface sites (Geissbühler and others, 2004), while energy minimization calculations of calcite surfaces in contact with either a monolayer of water molecules or hydroxyl ions imply that molecularly adsorbed water is favored energetically over hydroxylation, except at some steps and low-index calcite surfaces (Kerisit and others, 2003). Bond valence considerations further argue in favor of the non-dissociative adsorption of water molecules at the calcite surface (Fenter and Sturchio, 2005).

Some of the contradiction may reflect fundamental differences between the calcite-water and calcite-water vapor interfaces. For instance, X-ray reflectivity spectra of a saturated film of water on calcite did not show any difference whether the film of water had an acidic or alkaline $\mathrm{pH}$, implying that no calcium or carbonate ions were adsorbing onto the calcite surface (Fenter and others, 2000). In contrast, surface titrations of rhodochrosite, magnesite and dolomite at different values for $P_{\mathrm{CO}_{2}}$ and/or metal (Mn(II), Mg(II), Ca(II) ) concentrations clearly showed significant effects on the surface charge (Charlet and others, 1990; Pokrovsky and others, 1999a, 1999b), which is a strong indication that the mineral constituents adsorb from the bulk solution onto the mineral surface.

Even though there appear to be disparities between results from different lines of research on carbonate mineral-water interfaces, there are some striking agreements as well: (i) surface site densities are crystallographically controlled, and can therefore be 
predicted from truncation of the bulk lattice; (ii) water molecules in the vicinity of the mineral surface (that is, in the EDL) are highly ordered.

Pokrovsky and others (1999a) proposed that a thorough interpretation of electrokinetic surface charge measurements, which, for carbonate minerals, are more widely available than surface titration data, would be possible through a refinement of the existing SCM by considering a triple layer model (TLM) rather than a CCM description of the EDL. Within the CD-MUSIC approaches, the three-plane (TP) model is used to describe the charge distribution across the mineral-surface water interface. The hypotheses underlying the TP model, as described by Hiemstra and Van Riemsdijk (1996), are similar to those formulated for the TLM by Hayes and Leckie (1987). The TP model distinguishes between strongly and weakly adsorbed ions (Stern, 1924; Westall, 1986), and accounts for the structure and charge distribution of surface complexes within the EDL (Hiemstra and Van Riemsdijk, 1996). In addition, because it allows one to estimate the electrical potential at the outer Helmholtz plane, it can be used to interpret electrokinetic data (for example, Davis and Kent, 1990). The TP model also facilitates the interpretation of sorption of inorganic and organic ligands, as well as simple cations (Hiemstra and Van Riemsdijk, 1996).

\section{Dissolution, Growth and Surface Structure}

Extensive reviews have recently been published on carbonate mineral dissolution and growth (Morse and Arvidson, 2002; Morse and others, 2007). Several authors have related the dissolution and growth kinetics of carbonate minerals to surface speciation calculations using SCMs (see below). In particular, the $\mathrm{pH}$ dependence of dissolution kinetics has been explained in terms of changes in surface speciation for the carbonate minerals calcite (Van Cappellen and others, 1993; Arakaki and Mucci, 1995), magnesite (Pokrovsky and Schott, 1999a), dolomite (Pokrovsky and others, 1999b), rhodochrosite (Van Cappellen and others, 1993; Pokrovsky and Schott, 2002; Duckworth and Martin, 2003), and the zinc and nickel carbonates smithsonite and gaspeite (Pokrovsky and Schott, 2002). For dolomite growth, an SCM that accounts for sulfate adsorption has been used to discuss the possible causes for massive dolomite formation throughout geological time (Brady and others, 1996).

Pokrovsky and Schott (2002) proposed four pH-dependent dissolution mechanisms: (i) at the highest $\mathrm{pH}$, the dissolution rate depends on the concentration of the doubly protonated metal site $\equiv \mathrm{MeOH}_{2}^{+}$; (ii) at slightly lower $\mathrm{pH}$, the dissolution rate depends on the hydrolysis of surface metal centers and becomes $\mathrm{pH}$ independent; (iii) at even lower $\mathrm{pH}$, the proton-promoted dissolution rate is controlled by the concentration of $\equiv \mathrm{CO}_{3} \mathrm{H}^{\circ}$; (iv) within the lowest $\mathrm{pH}$ range, the dissolution rate is again $\mathrm{pH}$ independent because all surface groups are fully protonated. The $\mathrm{pH}$ values at which the different mechanisms become predominant depend on the mineral considered. For the more soluble carbonate minerals, such as calcite, the $\mathrm{pH}$ independent dissolution regime at very low $\mathrm{pH}$ typically falls outside the experimental window (for example, Rickard and Sjöberg, 1983; Pokrovsky and Schott, 2002; and the review by Morse and Arvidson, 2002). More recently, Duckworth and Martin (2003) were able to describe dissolution rate data for rhodochrosite with a simple rate equation based only on the concentrations of $\equiv \mathrm{CO}_{3} \mathrm{H}$ and $\equiv \mathrm{MnOH}_{2}^{+}$, but including site-specific dissolution rates for acute and obtuse steps.

Direct observations of cleavage surfaces demonstrate that dissolution and growth on relatively flat surfaces of carbonate minerals are related to the dynamics of crystallographically controlled edge pits, spirals and step edges. This has been shown by AFM imaging for carbonate mineral dissolution (Hillner and others, 1992; Dove and Hochella, 1993; Gratz and others, 1993; Stipp and others, 1994; Liang and others, 1996; Davis and others, 2000; Lea and others, 2001; Duckworth and Martin, 2003, 2004) and growth (Gratz and others, 1993; Dove and Hochella, 1993; Teng and others, 
2000; Shiraki and others, 2000; Higgins and others, 2002; Arvidson and others, 2006), and, for dissolution, also by scanning force microscopy (Jordan and Rammensee, 1998) and optical interferometry (MacInnis and Brantley, 1992; Lasaga and Lüttge, 2003; Lüttge and others, 2003). In earlier work, Rickard and Sjöberg (1983) observed that, near equilibrium, the surface area dependence of dissolution rates was different for different calcites, presumably due to differences in the types and abundances of reactive surface sites of the solids. Schott and others (1989) found that several orders of magnitude differences in dislocation densities (the starting point for edge-pit formation) caused only a minor (4\%) increase in the dissolution rate far from equilibrium, while, near equilibrium, the rate increased by a factor of two to three, as confirmed later by MacInnis and Brantley (1992). As a result of the increasing amount of observational data, significant effort has been devoted to develop process-based rate expressions that link growth and dissolution kinetics to the nature, distribution and surface manifestations of crystallographic defects (Teng and others, 2000).

The observed crystallographic controls on growth and dissolution kinetics emphasize the importance of accounting for structural differences among the various surface coordination sites. In their review of 2007, Morse and co-authors pointed out that a major limitation of the application of current SCMs to carbonate mineral dissolution and growth is that "this approach ... contains no intrinsic description of the variation in reactive site distribution (for example, attachment/detachment at kink sites and steps versus terraces)". A noteworthy exception to this statement is the dissolution model of Duckworth and Martin (2003) for single, cleaved rhodochrosite crystals. In this model, the surface sites that play a role in the dissolution mechanism are the edge sites-which were estimated to represent $\sim 1.5 \pm 0.5$ percent of the total number of surface sites by Duckworth and Martin. Within the framework of the CD-MUSIC approach, edge sites are explicitly represented, with a very similar concentration $(1.2 \%)$ when perfect cleavage rhombohedra of rhodochrosite are assumed (see below). The CD-MUSIC model for carbonate minerals also allows for the appearance of highly charged carbonate sites, at very low $\mathrm{pH}$ values. These sites may explain the previously reported, but so far unexplained, increase in the dissolution rate of magnesite with $\mathrm{pH}$ decrease below pH 2 (Pokrovsky and Schott, 1999). The CDMUSIC modeling approach therefore represents a promising tool to relate the surface chemical structure of carbonate minerals to their growth and dissolution kinetics.

THE CD-MUSIC MODEL

\section{Surface Structure}

Carbonate minerals can be divided into three structurally different groups: the calcite group, the aragonite group and the dolomite group. Carbonate units, $\mathrm{CO}_{3}^{2-}$, form the basic building blocks of all carbonate minerals, to which the divalent metal ions are coordinated. Table 3 lists the carbonate minerals considered here and gives an overview of the predominant cleavage and/or growth faces for each mineral, as reported in the literature. These faces are likely the predominant surfaces exposed to solution, although for an actual mineral sample the relative abundance of different crystal faces may depend on the provenance and sample preparation method.

To determine the structure of the dominant surfaces, mineral structures were taken from the library of the Diamond ${ }^{\odot}$ program for calcite and from published X-Ray diffraction data referred to below for the other minerals. While the orientation of cleavage and growth planes are well-established (for example, Klein and Hurlbut, 1985), the exact positions of these planes with respect to the actual lattice are not well known. This has been discussed in detail for oxides and silicate minerals by Koretsky and others (1998). For a number of carbonate minerals, the types of surface sites have been constrained by surface spectroscopic studies (for example, Stipp and Hochella, 
TABLE 3

Density (sites $\mathrm{nm}^{-2}$ ) of different sites present on the carbonate surfaces.

\begin{tabular}{|c|c|c|c|c|c|}
\hline Structural group & Mineral & Cleavage plane & $\mathrm{Me}-\mathrm{O}$ & $\mathrm{C}-\mathrm{O}$ & Ref \\
\hline \multirow[t]{4}{*}{ Calcite } & Calcite & $(10 \underline{14})$ & 4.9 & 4.9 & [1] \\
\hline & Rhodochrosite & $(1014)$ & 5.4 & 5.4 & [2] \\
\hline & Siderite & $(10 \underline{-14})$ & 5.6 & 5.6 & [2] \\
\hline & Magnesite & $(1014)$ & 5.7 & 5.7 & [3] \\
\hline Dolomite & Dolomite & $(1014)$ & $\begin{array}{l}2.6(\mathrm{Ca}-\mathrm{O}) \\
2.6(\mathrm{Mg}-\mathrm{O})\end{array}$ & 5.3 & [2] \\
\hline
\end{tabular}

The calculation of the densities is based on crystallographic data for the dominant cleavage plane. [1] ICDS 79674; [2] Effenberger and others (1981); [3] Markgraf and Reeder (1985).

1991; Pokrovsky and others, 2000) and atomistic simulation calculations (De Leeuw and Parker, 1998; Titiloye and others, 1998; Wright and others, 2001, 2002; Cygan and others, 2002; Kerisit and others, 2003; Rohl and others, 2003).

In the cases where bond lengths and site densities of surface sites are unknown, the CD-MUSIC model calculations assume ideal, unrelaxed surfaces as a first approximation (see also Bickmore and others, 2004, 2006). For calcite, XPS and LEED studies have shown the presence of an ordered surface at least $1 \mathrm{~nm}$ thick that is very similar to the bulk lattice (Stipp and Hochella, 1991). Koretsky and others (1998) tested five different methods to calculate the number of surface sites on mineral surfaces and compared the results for each method to available experimental values. Estimates based on the number of broken bonds gave the best agreement with site densities determined using the tritium exchange method. This method, where each broken bond of a near-surface atom is counted as one site, has been followed to calculate the site densities at carbonate mineral surfaces (table 3). Note, however, that the estimated site densities would require experimental verification using, for example, the $\mathrm{H}_{2} \mathrm{O}$ adsorption isotherm method or the tritium exchange method (Koretsky and others, 1998).

In the CD-MUSIC model, the types of sites present at the surface, and their coordination with atoms (or complex groups) of the bulk lattice, are constrained by the crystal planes exposed and the known bulk lattice structure. Thus, it is important to note that the site types are not free fitting parameters within the model. The pristine surface of a carbonate mineral consists of oxygen atoms which are either coordinated to carbon atoms within the carbonate groups or to metal ions (Ca(II), $\mathrm{Mg}$ (II), $\mathrm{Fe}$ (II), et cetera). Metal sites at hydrated carbonate mineral surfaces are coordinated to oxygens of $\mathrm{OH}^{-}$groups or water molecules.

Surface site concentrations may in principle vary with the morphology and size of the crystals. If faces other than the (1014) are exposed to solution, the ratio of metal to carbonate surface sites, $\equiv \mathrm{MeO}: \equiv \mathrm{CO}_{3}$, may deviate from the $1: 1$ stoichiometry. Variations in the site densities and $\equiv \mathrm{MeO}: \equiv \mathrm{CO}_{3}$ ratios can be accounted for in the CD-MUSIC model calculations. While for calcite the equilibrium and growth morphologies are dominated by the (10 $\overline{1} 4)$ cleavage planes, for other carbonate minerals, in particular those within the aragonite group, (110), (011), and (010) faces are also expressed, which implies non-stoichiometric $\equiv \mathrm{MeO}: \equiv \mathrm{CO}_{3}$ ratios.

The three-plane (TP) model is used to describe the charge distribution across the mineral-surface water interface (fig. 2). The plane of crystal lattice truncation cuts through the surface metal and carbon atoms (x-plane in fig. 2). The three planes that together form the Stern layer of the carbonate mineral-solution interface are: (i) the 
TABLE 4

Formal charges of the surface groups at different positions

\begin{tabular}{|c|c|c|c|c|c|}
\hline Site type & Position & Deprotonated & $1^{\text {st }}$ protonation & $2^{\text {nd }}$ protonation & $\begin{array}{l}\text { Sorption } \\
\text { reactions }\end{array}$ \\
\hline \multirow[t]{3}{*}{$\mathrm{Me}-\mathrm{O}$} & Face & $\equiv \mathrm{MeO}^{-5 / 3}$ & $\equiv \mathrm{MeOH}^{-2 / 3}$ & $\equiv \mathrm{MeOH}_{2}^{+1 / 3}$ & $\begin{array}{c}\mathrm{MeHCO}_{3}^{-2 / 3} \\
\equiv \mathrm{MeCO}_{3}^{-5 / 3}\end{array}$ \\
\hline & Edge & $\equiv \mathrm{MeO}^{-4 / 3}$ & $\equiv \mathrm{MeOH}^{-1 / 3}$ & $\equiv \mathrm{MeOH}_{2}^{+2 / 3}$ & $\begin{array}{c}\equiv \mathrm{MeHCO}_{3}^{-1 / 3} \\
\equiv \mathrm{MeCO}_{3}^{-4 / 3}\end{array}$ \\
\hline & Corner & $\equiv \mathrm{MeO}^{-}$ & $\equiv \mathrm{MeOH}^{\circ}$ & $\equiv \mathrm{MeOH}_{2}^{+}$ & $\begin{array}{c}\equiv \mathrm{MeHCO}_{3}^{\circ} \\
\equiv \mathrm{MeCO}_{3}^{-}\end{array}$ \\
\hline \multirow[t]{3}{*}{$\mathrm{C}-\mathrm{O}$} & Face & $\equiv \mathrm{CO}_{3}^{-1 / 3}$ & $\equiv \mathrm{CO}_{3} \mathrm{H}^{+2 / 3}$ & & $\equiv \mathrm{CO}_{3} \mathrm{Me}^{+5 / 3}$ \\
\hline & Edge & $\equiv \mathrm{CO}_{3}^{-2 / 3}$ & $\equiv \mathrm{CO}_{3} \mathrm{H}^{+1 / 3}$ & & $\equiv \mathrm{CO}_{3} \mathrm{Me}^{+4 / 3}$ \\
\hline & Corner & $\equiv \mathrm{CO}_{3}^{-}$ & $\equiv \mathrm{CO}_{3} \mathrm{H}^{\circ}$ & $\equiv \mathrm{CO}_{3} \mathrm{H}_{2}^{+}$ & $\equiv \mathrm{CO}_{3} \mathrm{Me}^{+}$ \\
\hline
\end{tabular}

0-plane, which cuts through the oxygen atoms in surface and adsorbed carbonate groups and hydroxylated surface metal ions, and where (de)protonation is the main charging reaction, (ii) the 1-plane, or inner Helmholtz plane, where inner-sphere complexation reactions take place, and (iii) the 2-plane, or outer Helmholtz plane, where outer-sphere complexes are located. The 0- and 1-planes are located close to each other. For inner-sphere complexation, this results in the contributed charge to be distributed between the 0 - and the 1-plane (fig. 2). In most of the model calculations presented here, outer-sphere complexation is ignored.

\section{CD-MUSIC Model Calculations}

A metal ion or carbonate group exposed at the surface may be coordinated differently to the underlying bulk lattice, depending on its position, either at a corner or edge site, or within a face. This will affect the charge neutralization of the (de)protonated oxygen, as is explained in detail by Hiemstra and others (1989a). The valence bond concept of Pauling describes how the degree of neutralization of charge of, say, a cation in the bulk structure can be expressed per bond, so that the neutralization of the cationic charge will be equal to the sum of the coordinated anionic charges reaching the cation. In other words, each bond represents a fractional charge. At a surface, the existence of broken bonds leads to a lower degree of neutralization and, by a simple bookkeeping of the fractional charges, the formal charge of a surface cation or anion can be calculated (table 4). Below, an example of formal charge calculations is given for calcite. The fractional charges are used in the surface charge calculations, following the CD-MUSIC approach, which accounts for the asymmetry of the charge distribution in the surface complexes. In the future, this approach may be refined, either by calculating the actual charges from fitting experimental adsorption data (Hiemstra and others, 1996), or from molecular dynamic simulations (Hiemstra and Van Riemsdijk, 2006) or semi-empirical model calculations like those applied to calcium carbonate dimers (Mao and Siders, 1997). 
The proposed CD-MUSIC model for carbonate minerals thus considers six types of sites, a face, edge and corner site for both the carbonate and the metal groups. The proton affinity of a surface group is calculated from the fractional charge of the surface oxygen by considering the valence bonds with its nearest neighbors, using the following expression (Hiemstra and Van Riemsdijk, 1996):

$$
\log K=-A\left(\sum_{j} s_{j}+V\right)
$$

where $A$ is a constant equal to $19.8, V$ is the valence of the surface oxygen $(V=-2)$, and $\Sigma_{j} s_{j}$ is the sum of valence bonds with the nearest neighbors, expressed in valence units (v.u.):

$$
\sum_{j} s_{j}=\sum_{i} s_{M e_{i}}+m \cdot s_{H}+n\left(1-s_{H}\right)
$$

where $\Sigma_{i} s_{M e_{i}}$ is the valence contribution of all the cations $\left(M e_{i}\right)$ surrounding the oxygen atom, either divalent metal or carbon ions. The last two terms in equation (2) are related to water adsorbed to the surface: $m$ and $n$ are the numbers of donating $(\equiv \mathrm{O}-\mathrm{H})$ and accepting $(\equiv \mathrm{O} \cdots \mathrm{H})$ hydrogen bridges, depending on whether the hydrogen bridge extends towards the solution or towards the surface. $s_{H}$ is the valence bond of a donating hydrogen bond, $\left(1-s_{H}\right)$ is the valence bond of an accepting hydrogen bond. The value for $s_{H}$ depends on the length of the $\mathrm{O}-\mathrm{H}$ bond and has an average value of 0.75 v.u. (0.68 to 0.88 v.u.; Bargar and others, 1997) per H. The contribution of the surrounding $M e$ ions $\left(s_{M e}\right)$ is calculated according to (Brown and Altermatt, 1985):

$$
s_{M e}=e^{\left(R_{0}-R\right) / b}
$$

where $R$ is the distance of the metal-oxygen or carbon-oxygen bond derived from the crystal structure. $R_{0}$ is the element specific distance and $b$ is a constant $(0.37 \pm 0.05 \AA)$; both parameters have been empirically determined from fitting equation (3) to the chemical connectivity (bonding) in inorganic crystals (Brown and Altermatt, 1985). Values for $R$ and $R_{0}$ reported for different bonds and bond lengths are listed in table 5 and are discussed below.

The values for $m$ and $n$ in equation (2) are the only free parameters when calculating the proton affinity of surface groups with equation (1). Steric considerations, however, put limits on $m$ and $n$ : a surface oxygen coordinated to one atom can, in principle, interact with two or three donating or accepting hydrogen bonds $(m+$ $n=2$ or 3 ), while surface oxygens coordinated to more than one atom can interact with one or two donating or accepting hydrogen bonds $(m+n=1$ or 2$)$ (Hiemstra and others, 1996). Recent molecular dynamics (MD) calculations suggest that the average number of hydrogen bridges to oxygen atoms on (hydr) oxy acid surfaces may range between 0.7 and 3.5 (Bickmore and others, 2004, 2006). In what follows, it is assumed that the metal and carbonate surface groups each have a fixed total number of hydrogen bridges, irrespective of their location on the surface. In addition, the number of hydrogen bridges is assumed not to vary with the degree of (de)protonation of the sites. Thus, the values of $m+n$ for the carbonate and metal sites represent two fitting parameters of the model. For each mineral surface considered here, the choice of values for $m$ and $n$ will be discussed, where possible in relation to molecular simulations.

In order to limit the number of adjustable model parameters, the complexation constants for calcium and carbonate sorption at the calcite surface reported by Van Cappellen and others (1993) were implemented without further modification. Impos- 
TABLE 5

Distances between the oxygen atom of the surface groups and their nearest metal or carbon neighbors in the bulk lattice $(R)$, and specific distance relative to the ligand $\left(R_{0}\right)$ after Brown and Altermatt (1985).

\begin{tabular}{|c|c|c|c|c|c|}
\hline Structural group & Mineral & Bond & $R_{0}(\AA)$ & $R(\AA)$ & Ref. \\
\hline \multirow[t]{17}{*}{ Calcite } & \multirow[t]{8}{*}{ Calcite } & \multirow[t]{6}{*}{$\mathrm{Ca}-\mathrm{O}$} & 1.967 & 2.369 & [1] \\
\hline & & & & 2.353 & [2] \\
\hline & & & & 2.360 & [3] \\
\hline & & & & $2.50 \pm 0.12$ & [4] \\
\hline & & & & 2.45 & {$[5]^{+}$} \\
\hline & & & & $2.32-2.72$ & [9] \\
\hline & & \multirow[t]{2}{*}{$\mathrm{C}-\mathrm{O}$} & 1.39 & 1.271 & {$[2]^{+}$} \\
\hline & & & & 1.285 & [3] \\
\hline & \multirow{3}{*}{ Magnesite } & \multirow[t]{2}{*}{$\mathrm{Mg}-\mathrm{O}$} & 1.693 & 2.102 & [3] \\
\hline & & & & $2.0-2.35(2.2)$ & {$[8]^{+}$} \\
\hline & & $\mathrm{C}-\mathrm{O}$ & 1.39 & $1.287^{\ddagger}-1.302$ & {$[3]^{\ddagger}$} \\
\hline & \multirow[t]{3}{*}{ Rhodochrosite } & $\mathrm{Mn}-\mathrm{O}$ & 1.79 & 2.218 & {$[6]^{+}$} \\
\hline & & & & 2.190 & [7] \\
\hline & & $\mathrm{C}-\mathrm{O}$ & 1.39 & 1.287 & {$[7]^{\ddagger}$} \\
\hline & \multirow[t]{3}{*}{ Siderite } & $\mathrm{Fe}-\mathrm{O}$ & 1.734 & 2.144 & [3] \\
\hline & & & & 2.2 & {$[9]^{+}$} \\
\hline & & $\mathrm{C}-\mathrm{O}$ & 1.39 & 1.287 & {$[3]^{\ddagger}$} \\
\hline \multirow[t]{5}{*}{ Dolomite } & \multirow[t]{5}{*}{ Dolomite } & $\mathrm{Ca}-\mathrm{O}$ & 1.967 & 2.382 & [3] \\
\hline & & & & $2.36-2.60(2.55)$ & [8] \\
\hline & & $\mathrm{Mg}-\mathrm{O}$ & 1.693 & 2.088 & [3] \\
\hline & & & & $2.04-2.52(2.42)$ & [8] \\
\hline & & $\mathrm{C}-\mathrm{O}$ & 1.39 & 1.285 & {$[3]^{+}$} \\
\hline
\end{tabular}

${ }^{\ddagger}$ Values used in this paper. References for distances: [1] Portlandite, ICSD 64950; [2] Calcite, ICSD 79674; [3] Effenberger and others, 1981; [4] measured at a hydrated calcite surface, Fenter and others, 2000; [5] Kerisit and others (2003); [6] Manganosite, ICSD 9864; [7] Rhodochrosite, ICSD 100677 (Effenberger and others, 1981); [8] Me-O octahedral distances in surface layer, Wright and others (2001); [9] assumed similar to $\mathrm{Mn}-\mathrm{O}$ and $\mathrm{Mg}-\mathrm{O}$; [10] $\mathrm{Ca}_{-} \mathrm{O}_{\text {water }}$ distance at the hydrated aragonite surface (De Leeuw and Parker, 1998)

ing the more recent values proposed by Pokrovsky and Schott (2002) resulted in overall less agreement between the model and the literature data used for model validation. More particularly, simulating $\zeta$-potential data at different added calcium concentrations using these authors' calcium adsorption constants leads to overestimation of the potential increase (see fig. 3).

In the TP model, the Stern-Grahame interfacial model is used to describe the charge-potential relationships for the two regions between the three planes. Simply put, this means that the layers between planes 0 and 1 and between 1 and 2 are serial capacitors, which have constant, but not necessarily equal, capacitances. For the innermost layer, the electrical charge resulting from inner sphere complexation reactions is distributed between the 0 - and the 1-planes (fig. 2). The charge distribution parameter $f$ defines the fraction of a sorbing ion that resides in the 0 -plane. From this, the charge distribution of a given surface complex in the 0 - and 1-planes $\left(B_{0}\right.$ and $\mathrm{B}_{1}$, see table 6) can be calculated. For example, for adsorption of a $\mathrm{Ca}^{2+}$ ion onto a surface carbonate, $f_{\equiv \text { СОзMe }}=0$, which means that all of the charge of the calcium is placed in the 1-plane. Therefore, $\mathrm{B}_{0}=-1$ due to the deprotonation of the surface 

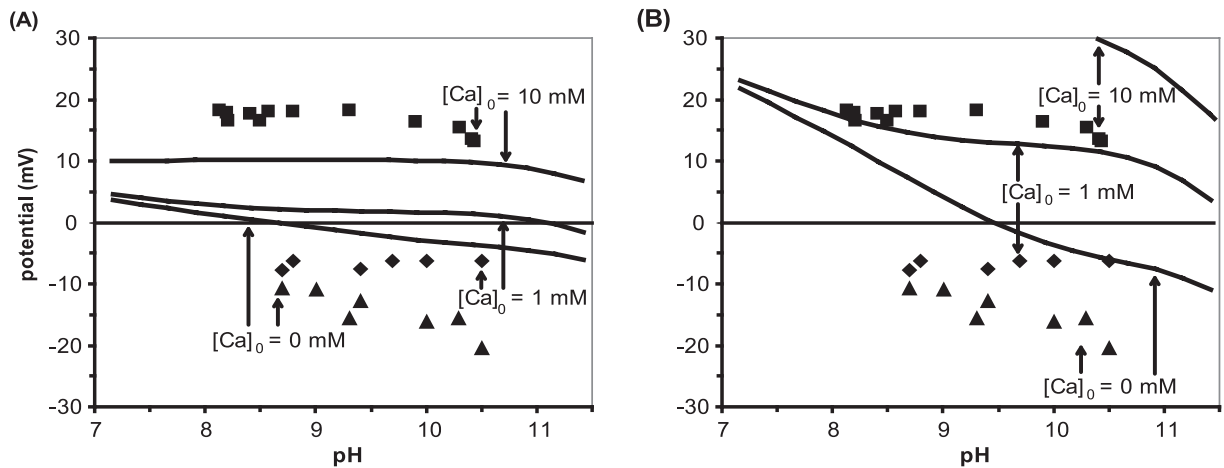

Fig. 3. (A) $\zeta$ potential pH-dependence data for calcite equilibrated in solutions containing different

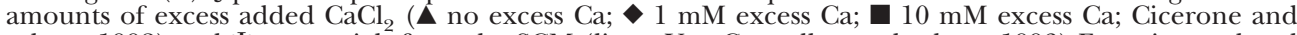

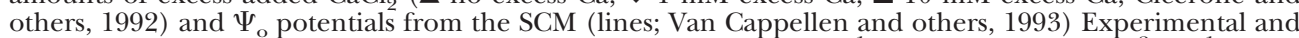
model conditions: $0.030 \mathrm{M} \mathrm{KCl}$; no gas phase; [Calcite] $=2.88 \mathrm{~g} \mathrm{~L}^{-1}$; surface area $0.015 \mathrm{~m}^{2} \mathrm{~kg}^{-1}$ (grain size $<10 \mu \mathrm{m}$ ). Other model parameters: $\mathrm{C}=30 \mathrm{~F} \mathrm{~m}^{-2}$; and as listed in table 2. (B) Symbols as in (A) and $\Psi_{\mathrm{O}}$ potentials from the SCM (lines; Pokrovsky and others, 2000) Experimental and model conditions: $0.030 \mathrm{M}$ $\mathrm{KCl}$; no gas phase; [Calcite] $=2.88 \mathrm{~g} \mathrm{~L}^{-1}$; surface area $0.015 \mathrm{~m}^{2} \mathrm{~kg}^{-1}$ (grain size $<10 \mu \mathrm{m}$ ). Other model parameters: $\mathrm{C}=17 \mathrm{~F} \mathrm{~m}^{-2}$; and as listed in table 2 .

carbonate group, and $\mathrm{B}_{1}=+2$ due to the addition of the $\mathrm{Ca}^{2+}$ ion. For bicarbonate (and similarly for carbonate) adsorption, $f_{\equiv \mathrm{MeHCO}_{3}}=0.4$, that is, $0.4 \cdot(+4)$ charge units of $\mathrm{C}$ from the adsorbing bicarbonate group is allocated to the 0-plane. Then, $\mathrm{B}_{0}=-(-1)+4 \cdot f_{\equiv \mathrm{MeHCO}_{3}}+(-2)=0.6$, where the first term corresponds to the dehydroxylation of the surface cation, the second term is the fraction of the charge of $\mathrm{C}$ in the 0 -plane, and the third term reflects the oxygen of the bicarbonate group placed in the 0 -plane (fig. 2). Likewise, for the 1-plane, $\mathrm{B}_{1}=4 \cdot\left(1-f_{\equiv \text { МeНCOз }_{3}}+2\right.$. $(-2)+1=-0.6$, where the first term is the remaining charge of $\mathrm{C}$, and the second and third terms are the charges contributed by two oxygen atoms and the proton from the bicarbonate, respectively. The values for $f$ are derived based on geometrical considerations (fig. 2). Although the values are somewhat arbitrary, the modeled $\zeta$-potentials and total net surface charges, which are used to assess the model performance, are insensitive to the $f$ values. The $f$ parameter is used here merely for consistency with the CD-MUSIC approach (Hiemstra and others, 1996). Sorption data would be necessary for a quantitative derivation of actual values.

Aqueous and surface speciation calculations were performed using the ECOSAT program (Keizer and Van Riemsdijk, 2002), for the conditions at which the simulated experimental data were collected. That is, surface site concentrations were obtained from the experimental solid densities and specific surface areas, and the ionic strength and type of electrolyte used in the experiments were imposed in the model. Equilibrium between solution, solid and gas phases was assumed, unless otherwise stated. Thermodynamic data for the $\mathrm{MeCO}_{3}-\mathrm{CO}_{2}-\mathrm{H}_{2} \mathrm{O}$ systems were taken from (i) Plummer and Busenberg (1982) for Me = Ca, (ii) Van Cappellen and others (1993) and the LLNL database for Me $=$ Fe, (iii) Van Cappellen and others (1993) for $\mathrm{Me}=\mathrm{Mn}$, (iv) Pokrovsky and Schott (1999) for $\mathrm{Me}=\mathrm{Mg}$. To account for ion pairing reactions with the electrolyte ions, the ECOSAT database was used. Electrostatic corrections for surface reactions were performed using the TP model; the capacitances of both layers were used as fitting parameters in the model simulations; $\mathrm{C}_{1}$ is the capacitance of the layer between the 0-and 1-planes; $\mathrm{C}_{2}$ is the capacitance of the layer between the 1 and 2-planes. As for any serial capacitors, the two relate to the total capacitance according to $\mathrm{C}^{-1}=\mathrm{C}_{1}^{-1}+\mathrm{C}_{2}^{-1}$. It was further assumed that $\mathrm{C}_{1} \geq \mathrm{C}_{2}$. 
TABLE 6

Surface reactions for different carbonate surfaces

\begin{tabular}{|c|c|c|c|c|c|c|c|c|c|}
\hline Calcite & $\mathrm{H}^{+}$ & $\mathrm{OH}^{-}$ & $\mathrm{Ca}^{2+}$ & $\mathrm{CO}_{3}^{2-}$ & $\equiv \mathrm{CO}_{3} \mathrm{H}^{\circ} \mathrm{a}$ & $\equiv \mathrm{CaOH}^{\circ \mathrm{b}}$ & $\log K$ & $\mathrm{~B}_{0}$ & $\mathrm{~B}_{1}$ \\
\hline$\equiv \mathrm{CO}_{3}^{-}$ & -1 & & & & 1 & & -3.58 & -1 & 0 \\
\hline$\equiv \mathrm{CO}_{3} \mathrm{H}_{2}^{+} \mathrm{c}$ & 1 & & & & 1 & & -8.30 & +1 & 0 \\
\hline$\equiv \mathrm{CO}_{3} \mathrm{Ca}^{+}$ & -1 & & 1 & & 1 & & $-2.8^{\mathrm{d}}$ & $-1^{e}$ & $2^{e}$ \\
\hline$\equiv \mathrm{CaOH}_{2}^{+}$ & 1 & & & & & 1 & 12.85 & +1 & 0 \\
\hline$\equiv \mathrm{CaO}^{-}$ & -1 & & & & & 1 & -24.73 & -1 & 0 \\
\hline$\equiv \mathrm{CaHCO}_{3}^{\circ}$ & 1 & -1 & & 1 & & 1 & $10.15^{d}$ & $0.6^{\mathrm{f}}$ & $-0.6^{\mathrm{f}}$ \\
\hline$\equiv \mathrm{CaCO}_{3}^{-}$ & & -1 & & 1 & & 1 & $1.55^{\mathrm{d}}$ & $0.6^{g}$ & $-1.6^{\mathrm{g}}$ \\
\hline Rhodochrosite & $\mathrm{H}^{+}$ & $\mathrm{OH}^{-}$ & $\mathrm{Mn}^{2+}$ & $\mathrm{CO}_{3}^{2-}$ & $\equiv \mathrm{CO}_{3} \mathrm{H}^{\circ} \mathrm{a}$ & $\equiv \mathrm{MnOH}^{\circ \mathrm{h}}$ & $\log K$ & $\mathrm{~B}_{0}$ & $\mathrm{~B}_{1}$ \\
\hline$\equiv \mathrm{CO}_{3}^{-}$ & -1 & & & & 1 & & -4.73 & -1 & 0 \\
\hline$\equiv \mathrm{CO}_{3} \mathrm{H}_{2}^{+}{ }^{\mathrm{a}}$ & 1 & & & & 1 & & -7.15 & +1 & 0 \\
\hline$\equiv \mathrm{CO}_{3} \mathrm{Mn}^{+}$ & -1 & & 1 & & 1 & & $-2.6^{\mathrm{d}}$ & $-1^{\mathrm{e}}$ & $2^{e}$ \\
\hline$\equiv \mathrm{MnOH}_{2}^{+}$ & 1 & & & & & 1 & 10.40 & +1 & 0 \\
\hline$\equiv \mathrm{MnO}^{-}$ & -1 & & & & & 1 & -22.28 & -1 & 0 \\
\hline$\equiv \mathrm{MnHCO}_{3}^{\circ}$ & 1 & -1 & & 1 & & 1 & $8.65^{d}$ & $0.6^{\mathrm{f}}$ & $-0.6^{\mathrm{f}}$ \\
\hline$\equiv \mathrm{MnCO}_{3}^{-}$ & & -1 & & 1 & & 1 & $0.15^{\mathrm{d}}$ & $0.6^{\mathrm{g}}$ & $-1.6^{\mathrm{g}}$ \\
\hline Siderite & $\mathrm{H}^{+}$ & $\mathrm{OH}^{-}$ & $\mathrm{Fe}^{2+}$ & $\mathrm{CO}_{3}^{2-}$ & $\equiv \mathrm{CO}_{3} \mathrm{H}^{\circ \mathrm{a}}$ & $\equiv \mathrm{FeOH}^{\circ \mathrm{h}}$ & $\log K$ & $\mathrm{~B}_{0}$ & $\mathrm{~B}_{1}$ \\
\hline$\equiv \mathrm{CO}_{3}^{-}$ & -1 & & & & 1 & & -4.73 & -1 & 0 \\
\hline$\equiv \mathrm{CO}_{3} \mathrm{H}_{2}^{+}{ }^{\mathrm{a}}$ & 1 & & & & 1 & & -7.15 & +1 & 0 \\
\hline$\equiv \mathrm{CO}_{3} \mathrm{Fe}^{+}$ & -1 & & 1 & & 1 & & $-1.6^{\mathrm{d}}$ & $-1^{\mathrm{e}}$ & $2^{e}$ \\
\hline$\equiv \mathrm{FeOH}_{2}^{+}$ & 1 & & & & & 1 & 11.07 & +1 & 0 \\
\hline$\equiv \mathrm{FeO}^{-}$ & -1 & & & & & 1 & -22.95 & -1 & 0 \\
\hline$\equiv \mathrm{FeHCO}_{3}^{\circ}$ & 1 & -1 & & 1 & & 1 & $8.75^{d}$ & $0.6^{\mathrm{f}}$ & $-0.6^{\mathrm{f}}$ \\
\hline$\equiv \mathrm{FeCO}_{3}^{-}$ & & -1 & & 1 & & 1 & $0.65^{d}$ & $0.6^{\mathrm{g}}$ & $-1.6^{\mathrm{g}}$ \\
\hline Magnesite & $\mathrm{H}^{+}$ & $\mathrm{OH}^{-}$ & $\mathrm{Mg}^{2+}$ & $\mathrm{CO}_{3}^{2-}$ & $\equiv \mathrm{CO}_{3} \mathrm{H}^{\circ \mathrm{a}}$ & $\equiv \mathrm{MgOH}^{\circ \mathrm{h}}$ & $\log K$ & $\mathrm{~B}_{0}$ & $\mathrm{~B}_{1}$ \\
\hline$\equiv \mathrm{CO}_{3}^{-}$ & -1 & & & & 1 & & -4.73 & -1 & 0 \\
\hline$\equiv \mathrm{CO}_{3} \mathrm{H}_{2}^{+a}$ & 1 & & & & 1 & & -7.15 & +1 & 0 \\
\hline$\equiv \mathrm{CO}_{3} \mathrm{Mg}^{+}$ & -1 & & 1 & & 1 & & $-2.2^{i}$ & $-1^{\mathrm{e}}$ & $2^{e}$ \\
\hline$\equiv \mathrm{MgOH}_{2}^{+}$ & 1 & & & & & 1 & 11.60 & +1 & 0 \\
\hline$\equiv \mathrm{MgO}^{-}$ & -1 & & & & & 1 & -23.48 & -1 & 0 \\
\hline$\equiv \mathrm{MgHCO}_{3}^{\circ}$ & 1 & -1 & & 1 & & 1 & $8.40^{\mathrm{i}}$ & $0.6^{\mathrm{f}}$ & $-0.6^{\mathrm{f}}$ \\
\hline$\equiv \mathrm{MgCO}_{3}^{-}$ & & -1 & & 1 & & 1 & $0.40^{\mathrm{i}}$ & $0.6^{\mathrm{g}}$ & $-1.6^{\mathrm{g}}$ \\
\hline Dolomite & $\mathrm{H}^{+}$ & $\mathrm{OH}^{-}$ & $\mathrm{Me}^{2+}$ & $\mathrm{CO}_{3}^{2-}$ & $\equiv \mathrm{CO}_{3} \mathrm{H}^{\circ \mathrm{a}}$ & $\equiv \mathrm{MeOH}^{\circ \mathrm{j}}$ & $\log K$ & $\mathrm{~B}_{0}$ & $\mathrm{~B}_{1}$ \\
\hline$\equiv \mathrm{CO}_{3}^{-}$ & -1 & & & & 1 & & -4.59 & -1 & 0 \\
\hline$\equiv \mathrm{CO}_{3} \mathrm{H}_{2}^{+}{ }^{\mathrm{a}}$ & 1 & & & & 1 & & -7.29 & +1 & 0 \\
\hline$\equiv \mathrm{CO}_{3} \mathrm{Mg}^{+}$ & -1 & & 1 & & 1 & & $-2.2^{i}$ & $-1^{e}$ & $2^{e}$ \\
\hline$\equiv \mathrm{CO}_{3} \mathrm{Ca}^{+}$ & -1 & & 1 & & 1 & & $-2.8^{\mathrm{d}}$ & $-1^{e}$ & $2^{e}$ \\
\hline$\equiv \mathrm{CaOH}_{2}^{+}$ & 1 & & & & & 1 & 14.12 & +1 & 0 \\
\hline$\equiv \mathrm{CaO}^{-}$ & -1 & & & & & 1 & -26.00 & -1 & 0 \\
\hline$\equiv \mathrm{CaHCO}_{3}^{\circ}$ & 1 & -1 & & 1 & & 1 & $10.15^{d}$ & $0.6^{\mathrm{f}}$ & $-0.6^{\mathrm{f}}$ \\
\hline$\equiv \mathrm{CaCO}_{3}^{-}$ & & -1 & & 1 & & 1 & $1.55^{\mathrm{d}}$ & $0.6^{\mathrm{g}}$ & $-1.6^{\mathrm{g}}$ \\
\hline$\equiv \mathrm{MgOH}_{2}^{+}$ & 1 & & & & & 1 & 10.81 & +1 & 0 \\
\hline$\equiv \mathrm{MgO}^{-}$ & -1 & & & & & 1 & -22.69 & -1 & 0 \\
\hline$\equiv \mathrm{MgHCO}_{3}^{\circ}$ & 1 & -1 & & 1 & & 1 & $8.40^{\mathrm{i}}$ & $0.6^{\mathrm{f}}$ & $-0.6^{\mathrm{f}}$ \\
\hline$\equiv \mathrm{MgCO}_{3}^{-}$ & & -1 & & 1 & & 1 & $0.40^{\mathrm{i}}$ & $0.6^{\mathrm{g}}$ & $-1.6^{\mathrm{g}}$ \\
\hline
\end{tabular}

Only reactions for the corner sites are given. $\log K, \mathrm{~B}_{0}$ and $\mathrm{B}_{1}$ values are the same for edge and face sites; the fractional charges differ for the three locations (see table 4 ) $;{ }^{\mathrm{a}} \mathrm{m}+\mathrm{n}=2.2 ;{ }^{\mathrm{b}} \mathrm{m}+\mathrm{n}=2.4 ;^{\mathrm{c}}$ only present as corner site; ${ }^{\mathrm{d}}$ values from Van Cappellen and others $(1993) ;{ }^{e} \mathrm{f}_{\equiv \mathrm{CO} 3 \mathrm{Me}}=0 ;{ }^{\mathrm{f}_{\mathrm{f}}} \mathrm{MeHCO}_{3}=0.4 ;{ }^{\mathrm{g}} \mathrm{f}_{\equiv \mathrm{MeCO}}=0.4$; ${ }^{\mathrm{h}} \mathrm{m}+\mathrm{n}=2.8$; ${ }^{\mathrm{i}}$ values from Pokrovsky and others $(1999 \mathrm{a})$; ; for Ca $\mathrm{m}+\mathrm{n}=2.4$, for Mg $\mathrm{m}+\mathrm{n}=2.8$.

ECOSAT calculates separate surface charges $\left(\sigma_{i}\right)$ and potentials $\left(\Psi_{i}\right)$ for the $0-, 1-$ and 2-planes. In what follows, the model output for $\Psi_{2}$ is assumed to represent the potential measured in electrophoretic mobility and streaming potential experiments, that is, the 2 plane is assumed to coincide with the shear plane (Sposito, 1984). This assumption is supported by the high capacitance values needed to simulate the 
experimental data. A high capacitance value implies a collapsed EDL, which suggests that the 2-plane and the plane of shear at which the $\zeta$-potential is measured are close together. The total net surface charge $(\sigma)$ carried by the $0-, 1-$ plus 2-planes is directly related to the surface speciation as follows (for example, Schindler and Stumm, 1987; Van Cappellen and others, 1993):

$$
\begin{aligned}
\sigma \mathrm{F}^{-1}=5 / 3 \times[\equiv & \left.\mathrm{CO}_{3} \mathrm{Me}^{+5 / 3}\right]+1 / 3 \times\left[\equiv \mathrm{MeOH}_{2}^{+1 / 3}\right]-1 / 3 \times\left[\equiv \mathrm{CO}_{3}^{-1 / 3}\right]-5 / 3 \\
& \times\left[\equiv \mathrm{MeO}^{-5 / 3}\right]-5 / 3 \times\left[\equiv \mathrm{MeCO}_{3}^{-5 / 3}\right]-2 / 3 \times\left[\equiv \mathrm{MeHCO}_{3}^{-2 / 3}\right]
\end{aligned}
$$

with $\sigma$ expressed in $\mathrm{C} \mathrm{m}^{-2}$, Faraday constant, $\mathrm{F}$, in $\mathrm{C} \mathrm{mol}^{-1}$, and surface concentrations $[\equiv \ldots]$ in $\mathrm{mol} \mathrm{m}^{-2}$.

In table 2, the stability constants of the surface reactions in the two-site SCM and CD-MUSIC models are compared for a number of carbonate minerals. Note that the charges of the surface complexes in the CD-MUSIC model are different from those in the two-site SCM, and that one surface reaction in the CD-MUSIC model is not listed in table 2, namely the second protonation of carbonate groups, which is assumed to occur only at corner sites based on geometrical considerations. The differences in protonation constants between the models illustrate the interdependencies of these constants. In the CD-MUSIC model, the proton affinity of the carbonate surface groups is slightly weaker, and of the $\equiv \mathrm{MeO}$ groups slightly stronger, than those in the original two-site SCM. On average, both models therefore predict the same $\mathrm{pH}_{\text {iep }}$ and $\mathrm{pH}_{\mathrm{zpc}}$ values. For all carbonate minerals, both models predict a negligible concentration of the fully deprotonated $\equiv \mathrm{MeO}$ groups across the whole $\mathrm{pH}$ range.

To summarize, assumptions common to both model approaches are: (i) surface site densities can be constrained from crystallographic data, (ii) surface complexation reactions are analogous to aqueous complexation reactions-equation (1) of the CD-MUSIC approach is founded on this assumption, (iii) mineral constituent ions are PDIs, and (iv) equilibrium can be reached between the mineral surface and the bulk solid, solution and gas phases. Major differences of the new CD-MUSIC model compared to the existing two-site SCM are: (i) the EDL consists of two layers that each have a constant capacitance, rather than one layer with a single capacitance, (ii) surface groups have fractional charges, compared to integer charges (for example, +1 or -2) in the original SCM and, (iii) the surface structure in the CD-MUSIC model is based on six sites, rather than two. In addition, in the CD-MUSIC model, charges of sorption complexes are distributed between (two of) the three planes within the EDL. Lastly, the potential at the 2-plane derived in the CD-MUSIC model is assumed to correspond to the experimentally measured $\zeta$ potential.

\section{RESULTS AND DISCUSSION}

The (1014) surface is the most stable crystal plane of calcite and, therefore, dominates its equilibrium and growth morphologies. All rhombohedral carbonates exhibit perfect [1014] cleavage, and most likely the cleavage planes dominate the exposed surfaces of ground samples of these minerals. Therefore, the CD-MUSIC model for the calcite-group minerals is based on the face, edge and corner sites exhibited by the cleavage rhombohedron (Titiloye and others, 1998). Figure 4 illustrates the smallest possible cleavage rhombohedron of calcite. The site densities of the metal and the carbonate groups along the (1014) surfaces are listed in table 3 . The relative amounts of face, edge, and corner sites were estimated by assuming that the particles are perfect cleavage rhombohedrons with average dimensions derived from the experimentally determined specific surface area or particle size.

Depending on its position-either at a corner, along an edge site or within a face-a metal or carbonate group is coordinated differently to the bulk lattice, thereby affecting its charge neutralization. For example, $\mathrm{a} \mathrm{Ca}^{2+}$ within the bulk calcite lattice 


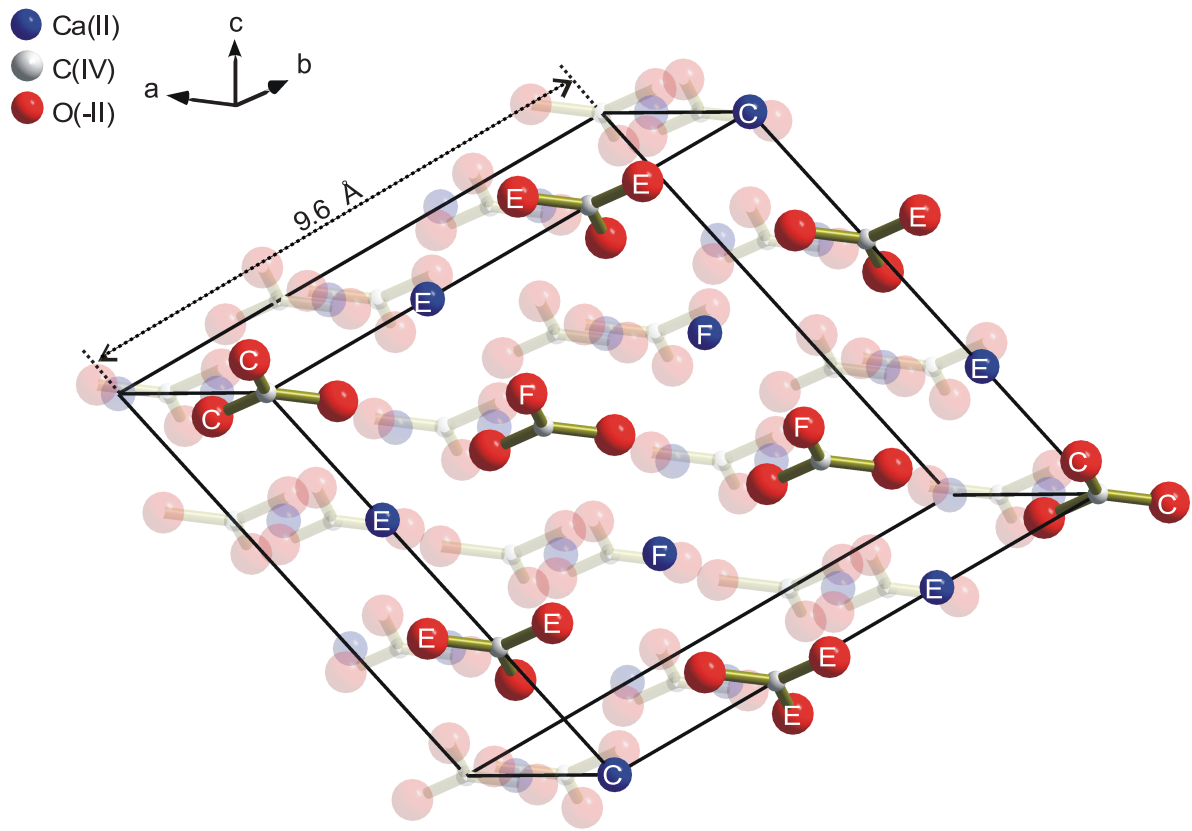

Fig. 4. Ball-and-stick model of the smallest possible cleavage rhombohedron of calcite, consisting of (1014) faces. For the front face, atoms are opaque and corner (C), edge (E) and face (F) sites are indicated for the oxygen in $\mathrm{CO}_{3}$ and the calcium atom that form $\mathrm{CaO}$ groups (oxygen atoms for the latter are not shown).

has a six-fold coordination, which means that per bond one third of a unit elementary charge is neutralized. $\mathrm{A} \mathrm{Ca}^{2+}$ within an exposed face has a coordination number of 5 (fig. 4), resulting in a residual fractional charge of $\equiv \mathrm{Ca}^{+1 / 3}$. Subsequently, when the binding oxygen is taken into account, the charge of this surface group is $\equiv \mathrm{CaO}^{-5 / 3}$. In this way, the formal charges for all surface groups, as listed in table 4, can be calculated.

\section{Calcite}

A relatively large number of electrokinetic studies have been carried out on calcite suspensions. The reported $\zeta$ - and streaming potentials, however, vary greatly and, at first glance, non-systematically (fig. 1). A careful inspection of the experimental conditions under which the various studies were performed suggests that the variable $\mathrm{pH}$ dependencies may reflect differences in solution composition and sample preparation, as well as variable degrees of disequilibrium between solid, solution and gas phase. The CD-MUSIC model offers a diagnostic tool to systematically analyze the electrokinetic data and constrain the possible causes of the large variability in the observed $\mathrm{pH}$ trends.

The experimental data included in the analysis were selected based on the completeness of solid, solution and, where appropriate, gas composition characterization during the experiments (table 1). Also taken into consideration were the reported equilibration times, and information on the purity and preparation of the calcite samples. The selected data and model simulation results are shown in figures 5 and 6 . The data of Moulin and Roques (2003) were omitted from the analysis, despite the fact that their methods seem robust and thoroughly described. However, their measured $\zeta$ potentials are negative over $\mathrm{pH}$ range 5 to 7.5 , in contrast with all other studies conducted under comparable experimental conditions, which imply positive poten- 
(A)

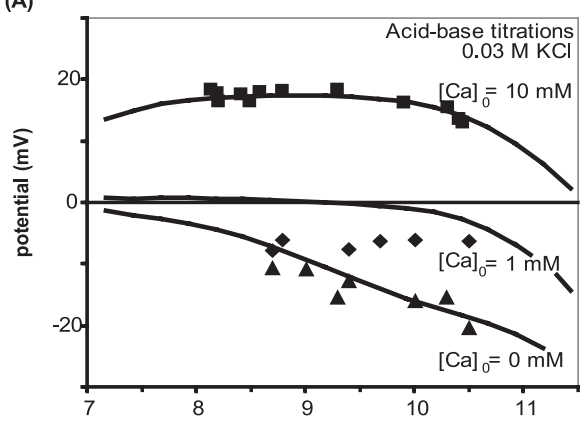

(C)

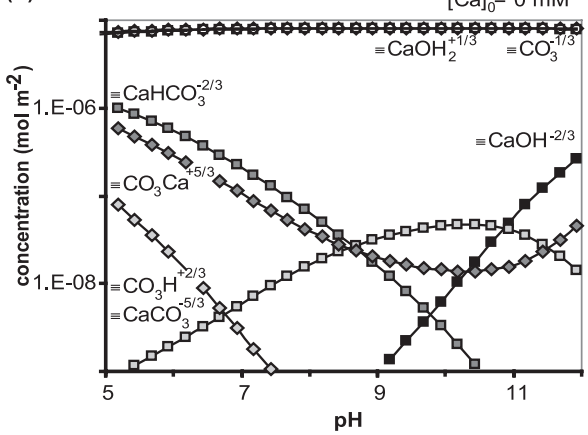

(B)

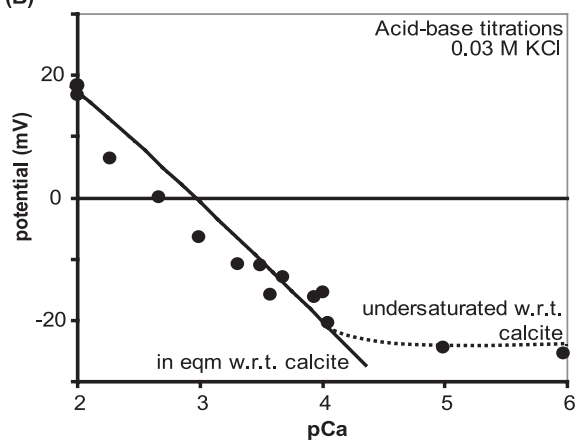

(D)

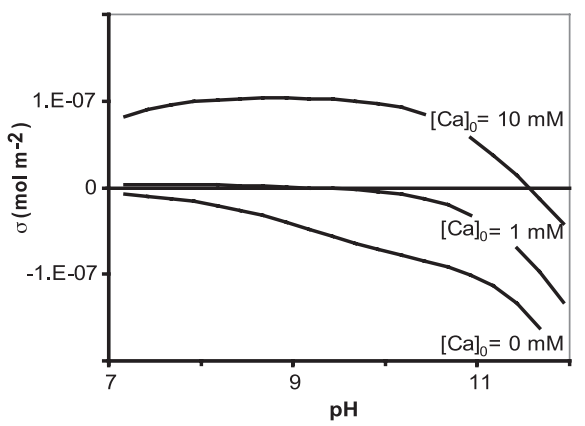

Fig. 5. (A) $\zeta$ potential pH-dependence data (symbols; Cicerone and others, 1992) and CD-MUSIC model (lines) for calcite equilibrated in solutions containing different amounts of excess added $\mathrm{CaCl}_{2}(\boldsymbol{\Delta}$ no excess $\mathrm{Ca} ; 1 \mathrm{mM}$ excess $\mathrm{Ca} ; \mathbf{1 0} \mathrm{mM}$ excess $\mathrm{Ca}$ ). Experimental and model conditions: $0.030 \mathrm{M} \mathrm{KCl}$; no gas phase; [Calcite] $=2.88 \mathrm{~g} \mathrm{~L}^{-1}$; surface area $0.015 \mathrm{~m}^{2} \mathrm{~kg}^{-1}$ (grain size $<10 \mu \mathrm{m}$ ). Other model parameters: $\mathrm{C}_{1}=\mathrm{C}_{2}=100 \mathrm{~F} \mathrm{~m}^{-2}$; and as listed in tables $3-6$. (B) $\zeta$ potential pCa-dependence data (O) Cicerone and others, 1992) and model (solid line) for calcite. Experimental and model conditions as in (A). Dotted line is model for conditions undersaturated with respect to calcite (see text). (C) Speciation of the face sites at the calcite surface equilibrated in a solution containing no added $\mathrm{CaCl}_{2}$. (D) Total net surface charge calculated from the model results according to equation 4 for the conditions in (A).

tials below a $\mathrm{pH}$ of approximately 8 . The latter is also predicted by the CD-MUSIC model calculations.

As a starting point, the $\zeta$-potential data from Cicerone and others (1992) were used. These data, which were obtained on suspensions of pre-cleaned calcite with additions of excess aqueous $\mathrm{Ca}^{2+}$ and in the absence of a gas phase, are shown in figures 3 and $5 \mathrm{~A}$ and $5 \mathrm{~B}$. As can be seen in figure 3, the existing SCMs can not simulate the potentials measured by Cicerone and others (1992). In contrast, the CD-MUSIC model reproduces the general trend of the response of the $\zeta$-potential to the addition of excess aqueous $\mathrm{Ca}^{2+}$ to the calcite suspensions (figs. $5 \mathrm{~A}$ and $5 \mathrm{~B}$ ). In particular, for $\mathrm{pH} \geq 7$, the model captures the switch from negative to positive $\zeta$-potentials upon addition of $\mathrm{Ca}^{2+}$ ions (fig. 5A). Model predictions and data diverge at $\mathrm{pCa}>4$ (fig. $5 \mathrm{~B})$. However, at very low dissolved $\mathrm{Ca}^{2+}$ concentrations, the assumption of equilibrium between calcite and solution may break down. As shown in figure $5 \mathrm{~B}$, the model can reproduce the measured $\zeta$-potentials at $\mathrm{pCa}>4$, when the solution is allowed to remain undersaturated with respect to calcite (dotted black line in fig. 5B; with a saturation index from 0 at $\mathrm{pCa}=4$ to -1.9 at $\mathrm{pCa}=6$ ). The model-derived surface speciation, for the case where no excess calcium is added, is illustrated in figure 5C. Over the entire $\mathrm{pH}$ range considered (5-12), the surface is dominated by $\equiv \mathrm{CaOH}_{2}^{+1 / 3}$ and $\equiv \mathrm{CO}_{3}^{-1 / 3}$ sites, whose opposite charges cancel out. As a result, only relatively small 
total net surface proton charges (eq 4) build up on the calcite surface (fig. 5D). According to figure $5 \mathrm{D}$, the isoelectric point $\left(\mathrm{pH}_{\mathrm{iep}}\right)$ and the point of zero charge $\left(\mathrm{pH}_{\mathrm{zpc}}\right)$ of calcite in equilibrium with a stoichiometric solution in the absence of a gas phase are both around 7. When excess dissolved $\mathrm{Ca}^{2+}$ is present, $\mathrm{pH}_{\mathrm{iep}}$ and $\mathrm{pH}_{\mathrm{zpc}}$ shift to higher values.

The model was subsequently applied to other literature data for calcite in open and closed systems, using the same set of parameter values as in figure 5 . Figures $6 \mathrm{~A}$ and 6B show the data of Pierre and others (1990) obtained in systems exposed to air or to a pure $\mathrm{N}_{2}$ atmosphere. These authors used ground and spherical calcite powders that were either washed or not. The data show very large differences in $\zeta$-potentials between washed (black symbols) and unwashed (other symbols) calcite powders, illustrating the crucial importance of sample preparation. The $\zeta$-potential data for ground calcite that was rinsed several times prior to the measurements are in good agreement with the predictions of the CD-MUSIC model, while data and model do not agree for ground and spherical calcite that was not washed. Furthermore, the disagreement increases with increasing $\mathrm{pH}$. A similar observation was made by Eriksson and others (2007; gray squares in fig. 1) for potential measurements carried out with suspensions of unwashed calcite open to the atmosphere. Most likely, the observed disagreement is due to disequilibrium between the solution and gas phase (for example Plummer and others, 1978; Chou and others, 1989) or to non-stoichiometric effects as is explained below.

Washing removes the smallest calcite particles produced during grinding. In the suspensions with unwashed calcite, the rapid dissolution of the finest calcite fraction causes a rapid consumption of protons and $\mathrm{H}_{2} \mathrm{CO}_{3}(\mathrm{aq})^{1}$. In open systems, the slow equilibration rate of $\mathrm{CO}_{2}(\mathrm{~g})$ at alkaline $\mathrm{pH}$, especially at $P_{\mathrm{CO}_{2}}<0.03 \mathrm{~atm}$ (Plummer and others, 1978), leads to undersaturation of the solution with respect to $\mathrm{CO}_{2}$ and, thus, to $\mathrm{pH}$ values exceeding the theoretical equilibrium values. Variable degrees of $\mathrm{CO}_{2}(\mathrm{~g})$ $\mathrm{CO}_{2}(\mathrm{aq})$ disequilibrium could thus explain the observed $\mathrm{pH}$ trends of potential measurements for calcite in solutions open to the atmosphere (figs. 6A-D). As shown in figures $6 \mathrm{~A}-\mathrm{D}$, potentials measured at near-neutral $\mathrm{pH}$ tend to agree with simulated $\Psi_{2}$ potentials for calcite in open systems, while potentials measured at high $\mathrm{pH}$ approach simulated $\Psi_{2}$ potentials for calcite in closed systems.

In addition to disequilibrium between solution and gas phase, the absence of equilibrium between solution and solid phase also appears to affect reported $\zeta$-potential measurements. Mishra (1978) "equilibrated" calcite with solution for only 30 minutes (table 1). As can be seen in figure 6C, $\zeta$-potentials measured by Mishra (1978) approach the modeled $\Psi_{2}$ potentials for calcite in equilibrium with solution and gas phase only in the vicinity of the solubility minimum $(\mathrm{pH} \approx 8.2)$. At lower and higher $\mathrm{pH}$, the measured potentials are closer to the potentials modeled for systems out of equilibrium with respect to calcite (fig. 6C), suggesting that an equilibration time of 30 minutes may not have been sufficient to reach thermodynamic equilibrium.

Washing calcite samples prior to electrophoretic measurements may also dissolve away non-stoichiometric surface layers or deposits. For example, Pierre and others (1990) report that the aqueous $\mathrm{Ca}^{2+}$ concentrations measured during the experiments performed under an $\mathrm{N}_{2}$ atmosphere with unwashed calcite were below those expected for stoichiometric equilibration with pure $\mathrm{CaCO}_{3}$. Their measured $\zeta$-potential values (black triangles in fig. 6B) fall between the values simulated for a stoichiometric (thin black line) and a $\mathrm{Ca}^{2+}(\mathrm{aq})$-deficient closed model system (thin dotted line), in line with the solution-chemistry data. The model-predicted surface potentials are not only sensitive to the stoichiometry of the solution, but also to that of the surface

${ }^{1}$ Conventionally representing $\mathrm{H}_{2} \mathrm{CO}_{3}^{\circ}(\mathrm{aq})+\mathrm{CO}_{2}(\mathrm{aq})$ 
(A)

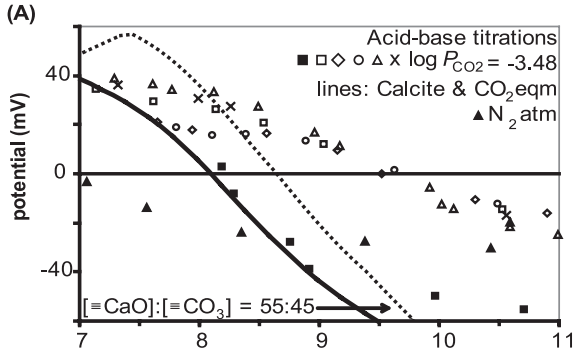

(C)
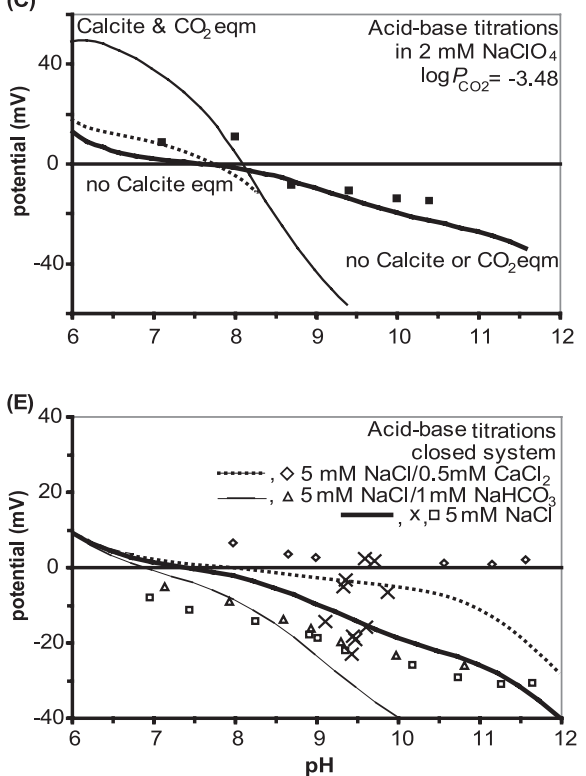

(G)

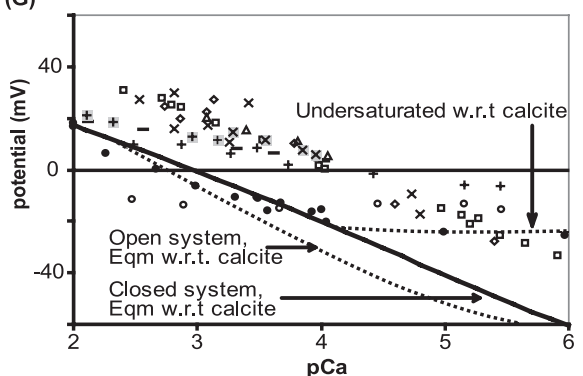

(B)

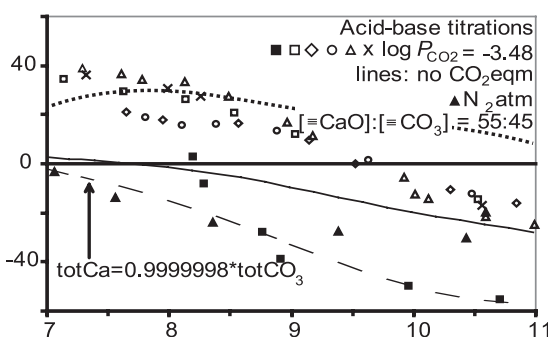

(D)

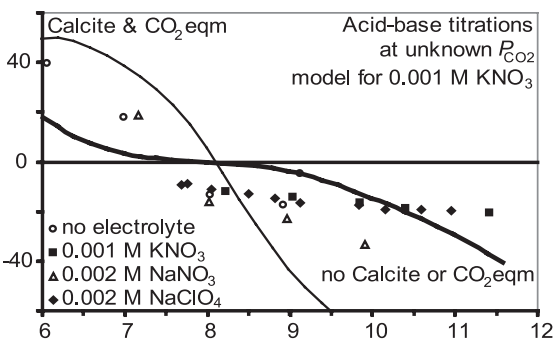

(F)
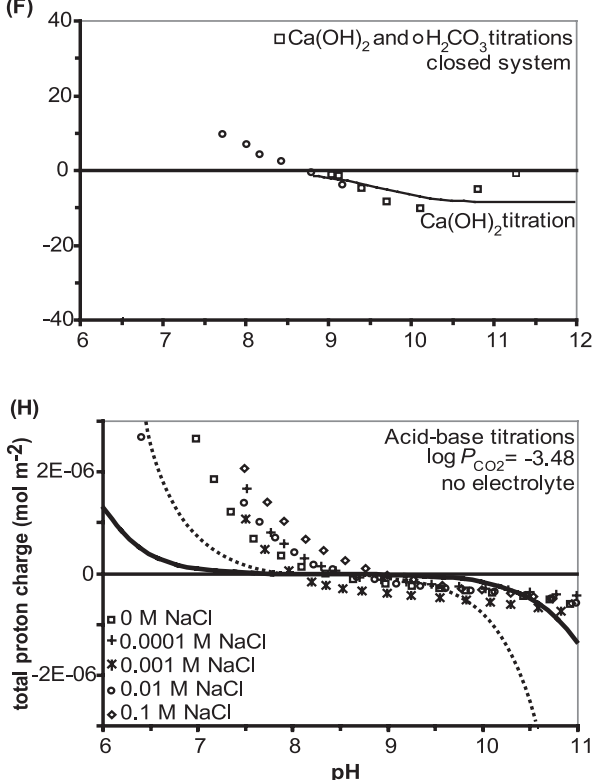

Fig. 6. Potential and net proton charge $\mathrm{pH}$ - and pCa-dependence data reviewed in table 1 and the CD-MUSIC model (lines) for calcite (Ct) at the same experimental conditions (table 1); closed symbols are washed and other symbols unwashed solids. Additional model parameters: $\mathrm{C}_{1}=\mathrm{C}_{2}=100 \mathrm{~F} \mathrm{~m}{ }^{-2}$; and as listed in tables 3-6. (A) Data from Pierre and others (1990) for ground Ct, no supporting electrolyte $(\mathbf{\square}, \triangle)$; $0.001 \mathrm{M} \mathrm{NaCl}(\times)$, and $0.01 \mathrm{M} \mathrm{NaCl}(\square)$; spherical Ct, no supporting electrolyte $(\bigcirc), 0.01 \mathrm{M} \mathrm{NaCl}(\diamond) ;$ and for Ca-deficient solution in $\mathrm{N}_{2}$ atmosphere $(\mathbf{\Delta})$; thick black line model $\Psi_{2}$ for rhombohedral Ct in $0.001 \mathrm{M}$ $\mathrm{NaCl}$ at $P_{\mathrm{CO} 2}=3.3 \times 10^{-4}$ atm, with $[\equiv \mathrm{CaOH}]_{\text {tot }}:\left[\equiv \mathrm{CO}_{3} \mathrm{H}\right]_{\text {tot }}=55: 45$ (dash-dot line for open system). (B) Data as in (A) and model $\Psi_{2}$ for rhombohedral Ct in $0.001 \mathrm{M} \mathrm{NaCl}$ in a closed system (solid line), with $[\equiv \mathrm{CaOH}]_{\text {tot }}:\left[\equiv \mathrm{CO}_{3} \mathrm{H}\right]_{\text {tot }}=55: 45$ (short-dashed line) and with totCa $=0.9999998 x_{\text {totCO}}$ (long-dashed line). (C) Data from Mishra (1978; and thin solid line); $\Psi_{2}$ results for no equilibrium with Ct (dashed line) and no equilibrium with Ct and gas phase (thick solid line). (D) Data at unknown $P_{\mathrm{CO} 2}$ from Sampat Kumar and others $(1971 ; \bigcirc)$, Somasundaran and others $(2005 ; \mathbf{\square})$, Patil and others $(1998 ; \triangle)$ and Hanumantha and others $(1989 ; \bullet)$. Also plotted are $\Psi_{2}$ results for Ct in 0.001 M KNO3 in a system in (thin line) or not in (thick 
itself. This is illustrated in figure $6 \mathrm{~B}$, where simulated potentials of calcite for a surface ratio $[\equiv \mathrm{CaOH}]_{\text {tot }}:\left[\equiv \mathrm{CO}_{3} \mathrm{H}\right]_{\text {tot }}=55: 45$ are shown (dash-dot and dash lines). As can be seen, even relatively small deviations from a 1:1 surface stoichiometry are predicted to fundamentally change the electrochemical surface properties of carbonate minerals.

The importance of careful cleaning of calcite samples has long been recognized by experimentalists. For instance, Douglas and Walker (1950) boiled their calcite samples in distilled water for an hour, "a treatment found to give reproducible behavior from one batch of material to another, as was shown by the constancy of the calculated $\zeta$ potentials towards water and $\mathrm{N} / 10 \mathrm{Na}+$ ion buffer of $\mathrm{pH} 9$, and to regain the initial state after following through the effect of various electrolytes". Recently, $\mathrm{Na}$ and others (2007) observed the presence of nanostructures along step edges of calcite and rhodochrosite, after cleaving the crystals and storing them for a few hours at relative humidities of 20 to 80 percent. These nanostructures exhibited local surface potentials that were $\sim 120$ (calcite) and $\sim 200$ to $300 \mathrm{mV}$ (rhodochrosite) higher than the average surface potentials.

The effect of sample preparation is further illustrated by the data of Thompson and Pownall (1989) who measured streaming potentials in systems closed to the atmosphere (figs. $6 \mathrm{E}$ and $6 \mathrm{~F}$ ). The crosses on figure $6 \mathrm{E}$ correspond to $\mathrm{pH}$ and streaming potential values measured simultaneously using crushed and sieved, but unwashed, calcite suspended in an identical salt solution, following the same procedure for each set of measurements. Nonetheless, the measured $\mathrm{pH}$ values range across one unit, while the potentials vary from slightly positive to about $-20 \mathrm{mV}$. The poor reproducibility of electrokinetic measurements should be kept in mind when comparing model output and data. For example, figure $6 \mathrm{~F}$ shows additional data by the same authors obtained in various electrolyte solutions using different titration techniques, with the corresponding model-predicted potential-pH curves. At first glance, model and data do not agree particularly well. However, considering the potential artifacts related to sample cleaning, solution and surface stoichiometry, plus the nonattainment of equilibrium, the model-predicted and observed trends are actually in reasonable agreement.

Figure 6G shows the dependence of surface potentials on the calcium concentration in solution. Note that some data were obtained at constant $\mathrm{pH}$ by varying the calcium concentration (circles, plusses and bars), while most data were obtained by measuring calcium concentrations in solution after potentials were measured in a suspension where the $\mathrm{pH}$ was adjusted by acid or base titrations. Furthermore, most data were measured in systems open to the atmosphere. The model curves depicted are for closed and open systems in $0.03 \mathrm{M} \mathrm{KCl}$ and for a system undersaturated with respect to calcite (as in fig. 5B). The discrepancies between model and data cannot be attributed solely to disequilibrium between the solution and gas phase, as the majority of the data fall outside the envelope of the model curves for closed and open systems. One explanation could be varying degrees of undersaturation with respect to calcite (see discussion of fig. 5B). However, extremely low carbonate concentrations would be

\footnotetext{
line) equilibrium with $\mathrm{Ct}$ and the atmosphere. (E) Data from Thompson and Pownall (1989) for equilibration $(X)$ and acid-base titrations of Ct in $5 \mathrm{mM} \mathrm{NaCl}(\square), 5 \mathrm{mM} \mathrm{NaCl} / 1 \mathrm{mM} \mathrm{NaHCO},(\triangle), 5 \mathrm{mM} \mathrm{NaCl} / 0.5$ $\mathrm{mM} \mathrm{CaCl}_{2}(\diamond)$, and for $\mathrm{Ca}(\mathrm{OH})_{2}(\square)$ and $\mathrm{H}_{2} \mathrm{CO}_{3}$ titrations in $5 \mathrm{mM} \mathrm{NaCl} / 1 \mathrm{mM} \mathrm{NaHCO} \mathrm{C}_{3}(\bigcirc)$. (F) Potential

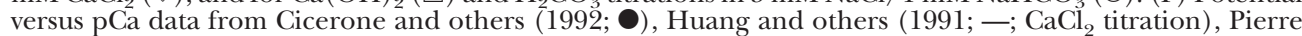
and others $\left(1990\right.$; for $\mathrm{CaCl}_{2}$ titration at $\mathrm{pH} 8.5(+)$ and $10.35(\bigcirc)$ in $0.01 \mathrm{M} \mathrm{NaCl}$, and acid-base titrations in $0.001 \mathrm{M} \mathrm{NaCl}(\times), 0.01 \mathrm{M} \mathrm{NaCl}(\square)$, and $0.1 \mathrm{M} \mathrm{NaCl}(\diamond))$ and Foxall and others $(1979)$ in $0.01 \mathrm{M} \mathrm{NaCl}(\triangle)$, $0.05 \mathrm{M} \mathrm{NaCl}(\mathrm{X})$, and $0.15 \mathrm{M} \mathrm{NaCl}( \pm)$. (G) Net proton charge density for calcite at different electrolyte concentrations (Eriksson and others, 2007) and model net proton charge density (solid line) and total net surface charge $(\sigma$, dashed line).
} 
required to cause undersaturation at low pCa (high calcium concentrations). Alternatively, the deviation of the observed potentials toward more positive values reflects artifacts related to the use of unwashed calcite samples.

In contrast to the large number of published studies presenting surface potential measurements for calcite, there is, to the authors' knowledge, only one publication reporting calcite surface charge measurements. Mainly this is due to the interference of the relatively fast dissolution and precipitation kinetics of calcite during acid-base titrations. Eriksson and others (2007) calculated net proton surface charges of calcite by correcting the net consumption of protons by calcite suspensions in contact with the atmosphere during acid-base titrations for the proton consumption by the supernatant alone (fig. $6 \mathrm{H}$ ). At the high end of the $\mathrm{pH}$ range investigated, the model over-predicts the charge build-up, while at the low end the opposite is true. While the discrepancy between the experimental data and the model predictions may in part be due to dissolution and precipitation artifacts that were not accounted for (and for which calcite is notorious), the relatively short equilibration times of the calcite suspensions (1 hour) may also have prevented the attainment of thermodynamic equilibrium.

Overall, the uncertainties surrounding the nature and magnitude of potential artifacts in electrokinetic and acid-base titration studies with calcite suspensions prevent a straightforward validation of the surface model. However, both the experimental results and the model simulations indicate that clean, well-characterized mineral surfaces and a detailed knowledge of the in situ solution composition are essential to interpret electrokinetic measurements in terms of surface speciation. For a closed system containing initially only pure calcite and an inert background electrolyte, the model-predicted surface speciation of calcite is schematically shown in figure 7 for three different $\mathrm{pH}$ values $(5,8,11)$, assuming that the solid and solution remain in thermodynamic equilibrium (conditions are the same as in fig. 5C). At low pH, adsorption of bicarbonate and calcium ions is a dominant charge-determining process. With increasing $\mathrm{pH}$, the adsorption of lattice ions decreases in importance, while, at high $\mathrm{pH}(\sim 11)$, deprotonation of water molecules sorbed to surface calcium sites becomes a significant source of negative charge. Thus, even for the most simple carbonate mineral-water system, surface charging is an inherently complex process.

\section{Rhodochrosite, Siderite, Magnesite and Dolomite}

Far fewer studies have been devoted to the surface chemistry of divalent metal carbonate minerals other than calcite. For the four minerals considered here, both surface charge and $\zeta$-potential data are available (figs. 8 and 9). In addition, the data extend to $\mathrm{pH}$ values below 7 , because these minerals dissolve much slower than calcite under acidic conditions.

The CD-MUSIC model fits to experimental $\zeta$-potential and surface charge data versus $\mathrm{pH}$ for rhodochrosite are shown in figure 8; the corresponding model parameters are listed in tables 3 to 6 . The total number of hydrogen bonds, the proton affinities (equation 1), and the capacitances $\mathrm{C}_{1}$ and $\mathrm{C}_{2}$ were varied by trial and error to obtain visual fits to the $\zeta$-potential data (fig. $8 \mathrm{~A}$ ) plus the surface charge data at $P_{\mathrm{CO}_{2}}=$ $0.005 \mathrm{~atm}$ (fig. $8 \mathrm{~B}$ ), and then kept constant when simulating the surface charge at $P_{\mathrm{CO}_{2}}=0.5 \mathrm{~atm}$ (fig. $8 \mathrm{C}$ ). High values for $\mathrm{C}_{1}$ and $\mathrm{C}_{2}$ were required to simulate the relatively high surface charges observed. For the model simulations presented in figure $8, \mathrm{C}_{1}=\mathrm{C}_{2}=100 \mathrm{~F} \mathrm{~m}^{-2}$. Generally, the outer capacitance is assumed to be smaller than the inner capacitance (for example, Yates and others, 1974; Davis and others, 1978; Hiemstra and Van Riemsdijk, 1996). Recently, however, Sverjensky (2005) proposed to estimate $\mathrm{C}_{2}$ by assuming $\mathrm{C}_{2}=\mathrm{C}_{1}$ for a broad range of minerals. Our model simulation results are consistent with this proposal. With lower inner or outer capacitance values, 

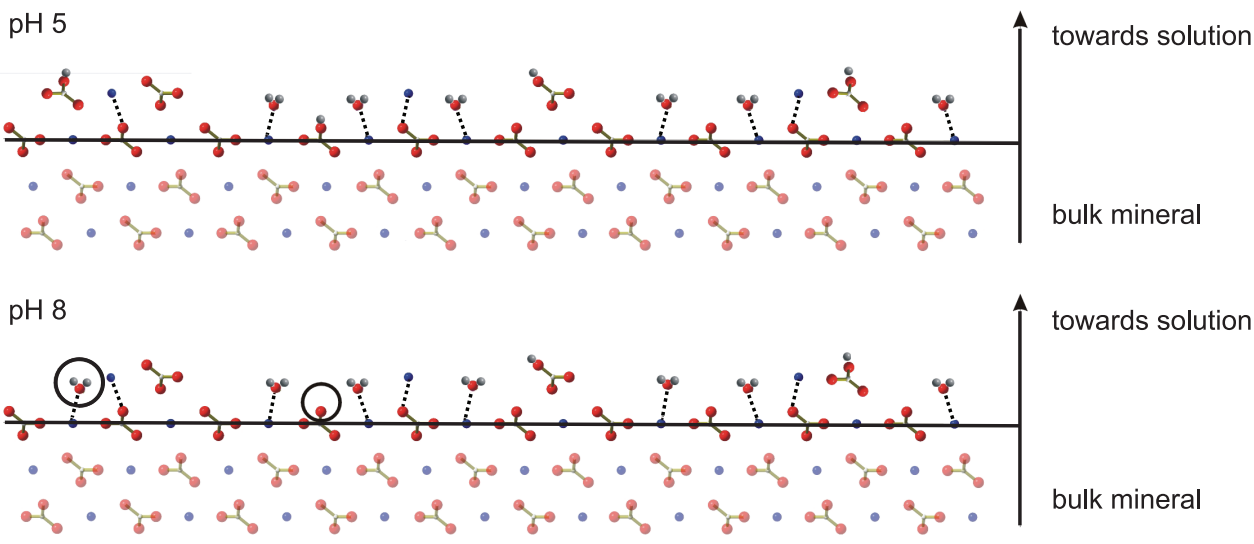

$\mathrm{pH} 11$

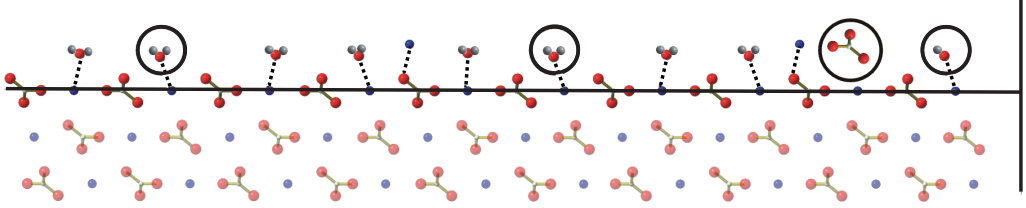

towards solution

- Calcium $:=$ Carbon $\bullet=$ Oxygen $\bullet=$ Proton

Fig. 7. Ball-and-stick model of the surface speciation of calcite at $\mathrm{pH} 5,8$ and 11. Surface groups are drawn opaque, atoms that are part of the bulk mineral are drawn transparent. Differences in surface speciation between $\mathrm{pH} 5$ and 8 are encircled in the sketch for $\mathrm{pH}$ 8; differences in surface speciation between $\mathrm{pH} 8$ and 11 are encircled in the sketch for $\mathrm{pH} 11$.

the surface potential data of rhodochrosite could be reproduced, but the surface charge data were significantly underestimated. High capacitances of carbonate mineralwater interfaces have been noted previously (Van Cappellen and others 1993), and were attributed to a high degree of molecular ordering near the mineral surface.

The model reproduces the experimental dependence of the $\zeta$-potential of rhodochrosite on $\mathrm{pH}$ measured by Pokrovsky and Schott (2002) (fig. 8A). The deviations between model and data may in part be due to variations in the dissolved $\mathrm{Mn}^{2+}$ concentration that were measured by Pokrovsky and Schott (fig. 8A). The range of aqueous $\mathrm{Mn}^{2+}$ concentrations reported by the authors also implies that the assumption of thermodynamic equilibrium between the bulk solid and solution does not hold over the entire $\mathrm{pH}$ range studied, that is, the variation in $\mathrm{Mn}^{2+}$ concentration was larger than expected if the mineral suspension were at equilibrium. Therefore, the assumption of equilibrium between the solid and solution was relaxed and the measured values of the $\mathrm{Mn}^{2+}$ and carbonate concentrations were imposed in the model simulations (fig. 8A). The observed downward shift in $\mathrm{pH}_{\mathrm{zpc}}$ from $\sim 7$ to $\sim 6$ when $P_{\mathrm{CO}_{2}}$ increases from 0.005 to 0.5 atm is correctly captured by the CD-MUSIC model (figs. $8 \mathrm{~B}$ and $8 \mathrm{C}$ ). This shift reflects enhanced carbonate adsorption to the mineral surface. The steepness of the total net surface charge versus $\mathrm{pH}$ at $P_{\mathrm{CO}_{2}}=0.5$ atm, and for $\mathrm{pH}>\mathrm{pH}_{\mathrm{zpc}}$ at $P_{\mathrm{CO}_{2}}=0.005$ atm is not well reproduced by the model, however. Possibly, this reflects non-equilibrium conditions during the (fast) acid-base titration experiments. The model-predicted $\mathrm{pH}$ dependent surface speciation of rhodochrosite in $0.032 \mathrm{M} \mathrm{NaCl}$ and $0.005 \mathrm{~atm} P_{\mathrm{CO}_{2}}$ is illustrated in figure $8 \mathrm{D}$. Note the 

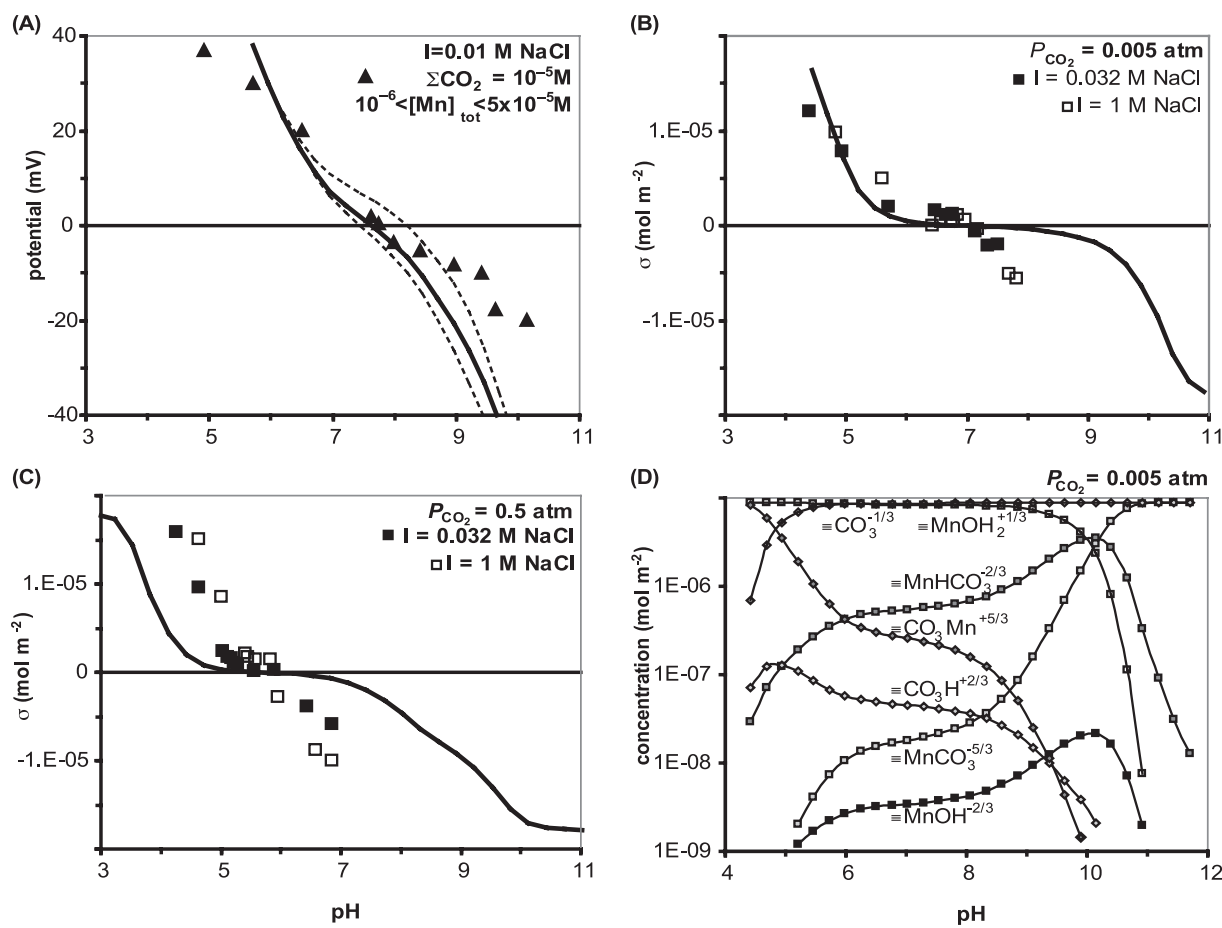

Fig. 8. Potential and total net surface charge data and CD-MUSIC model (lines) for rhodochrosite at the same experimental conditions (table 1). (A) $\zeta$ potential data $\left(\boldsymbol{\Delta} ;\right.$ Pokrovsky and Schott, 2002); $\Sigma \mathrm{CO}_{2}=$ $10^{-5} \mathrm{M} ; 10^{-6}<[\mathrm{Mn}]_{\text {total }}<5 \times 10^{-5} \mathrm{M}$; [rhodochrosite] $=4 \mathrm{~g} \mathrm{~L}^{-1}$. (B) Surface charge $\mathrm{pH}$-dependence data $\left(\square, \mathbf{\square}\right.$; Charlet and others, 1990) and model; [rhodochrosite] $=2.5 \mathrm{~g} \mathrm{~L}^{-1}$. (C) Surface charge data $(\square, \mathbf{\square}$; Charlet and others, 1990) and model; [rhodochrosite] $=2.5 \mathrm{~g} \mathrm{~L}^{-1}$. (D) Speciation of the face sites at the rhodochrosite surface in $0.032 \mathrm{M} \mathrm{NaCl}$ and $P_{\mathrm{CO}_{2}}=0.005 \mathrm{~atm}$. Additional model parameters: $\mathrm{C}_{1}=\mathrm{C}_{2}=100$ $\mathrm{F} \mathrm{m}^{-2}$; and as listed in tables 3-6.

significant differences in the model-derived surface chemical structures for calcite in a closed system and rhodochrosite in an open system (compare figs. 5C and 8D).

The model parameters used in the simulations for siderite, magnesite and dolomite shown in figure 9 are listed in tables 3 to 6 . The total number of hydrogen bonds and the values of $\mathrm{C}_{1}$ and $\mathrm{C}_{2}$ were all assumed identical to those for rhodochrosite. The proton affinities were calculated with the bond lengths selected in table 5 . No additional fitting of the model parameters was performed. In all cases, a number of model simulations were run to bracket the conditions in the experiments: the model envelopes in figure 9 encompass the reported ranges of measured concentrations of total metal and total $\mathrm{CO}_{2}$. For magnesite, simulations assuming both solid-solution equilibrium and non-equilibrium are shown (fig. 9D). As for calcite and rhodochrosite, the simulation results emphasize the high sensitivity of the surface charges and potentials to changes in the concentrations of the dissolved mineral constituents and to the degree of disequilibrium.

One feature that cannot be accounted for by the model simulations, even when taking into account the full range of variation in solution composition, is the surface potential data of magnesite and dolomite at $\mathrm{pH}<5$ (figs. 9C and 9E). The measured potentials are on the order of 20 to $40 \mathrm{mV}$, while the model predicts values in the range 100 to $160 \mathrm{mV}$. Possibly, some of the imposed model parameter values are inadequate. For instance, the magnitudes of the surface charges and potentials of magnesite at $\mathrm{pH}$ 

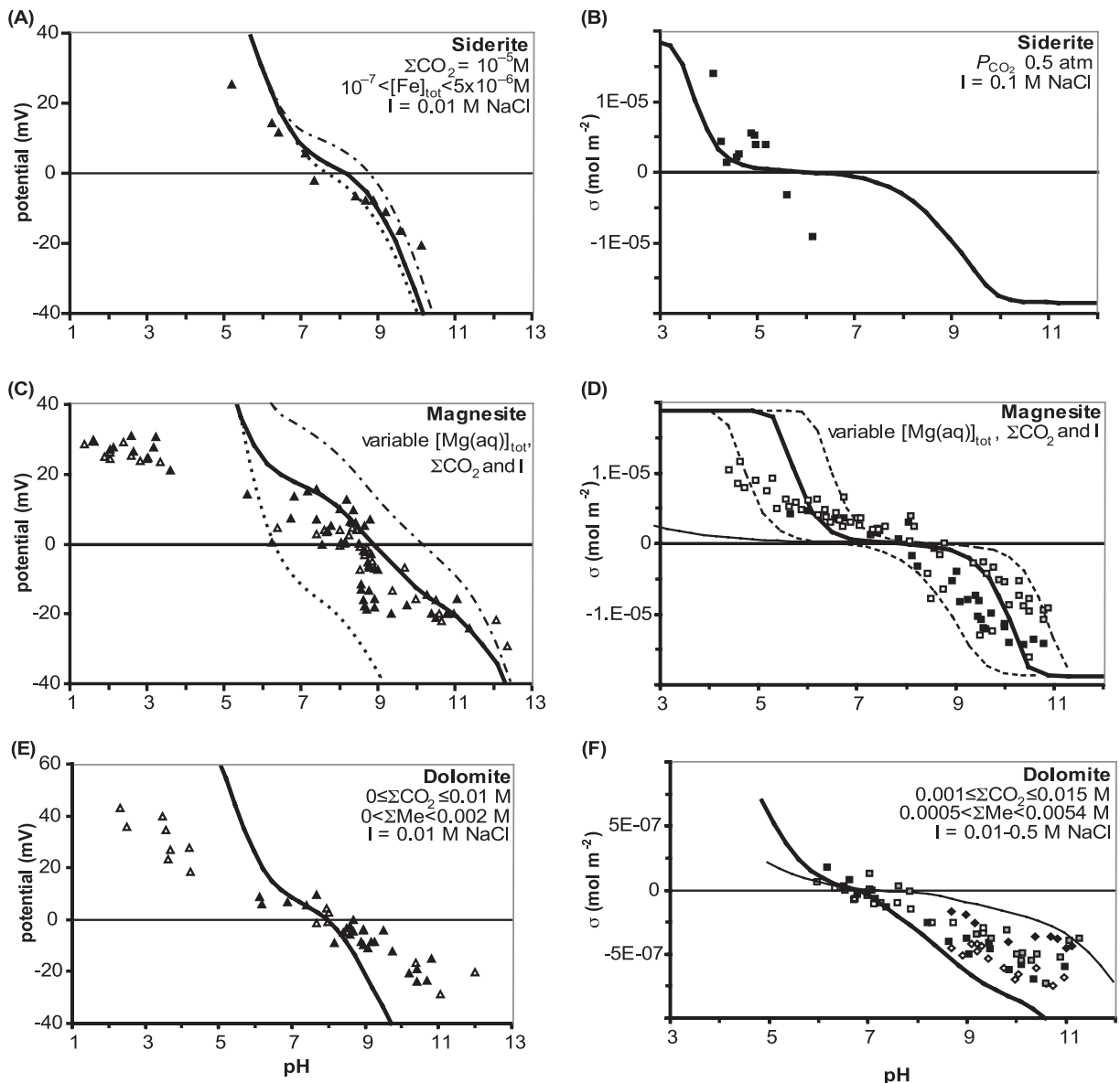

Fig. 9. Potential and total net surface charge data and CD-MUSIC model (lines) for siderite, magnesite and dolomite (conditions, see table 1). (A) $\zeta$ potential data $(\boldsymbol{\Delta}$; Pokrovsky and Schott, 2002) for siderite; $\sum \mathrm{CO}_{2}=10^{-5} \mathrm{M} ; 10^{-7}<[\mathrm{Fe}]_{\text {total }}<5 \times 10^{-6} \mathrm{M} ;[$ siderite $]=4 \mathrm{~g} \mathrm{~L}^{-1} ;$ model at $[\mathrm{Fe}]_{\text {total }}=10^{-6} \mathrm{M}$ (thick solid line), upper (dash-dot) and lower (dash) $[\mathrm{Fe}]_{\text {total }}$. (B) Surface charge data ( $\mathbf{\square}$; Charlet and others, 1990) for siderite and model $($ at $I=0.1 \mathrm{M} \mathrm{NaCl}) ; P_{\mathrm{CO}_{2}}=0.5 \mathrm{~atm} ;$ [siderite] $=2.5 \mathrm{~g} \mathrm{~L}^{-1}$. (C) streaming potential $(\mathbf{\Delta})$ and electrophoresis $(\triangle)$ data (Pokrovsky and others, 1999a) for magnesite; $I=0.0005-0.270 \mathrm{M} ; \Sigma \mathrm{CO}_{2}=$ $0.0-0.039 \mathrm{M} ; 5.78 \times 10^{-6}<[\mathrm{Mg}]_{\text {tal }}<0.0870 \mathrm{M} ;$ model at $\mathrm{pH}_{\text {ep }}$ conditions (thick solid line; $\mathrm{pMg}=3.3$ and $\left.\Sigma \mathrm{CO}_{2}<0.003 \mathrm{M}\right), \Sigma \mathrm{CO}_{2}=0.026 \mathrm{M}$ (dash-dot), $\Sigma \mathrm{CO}_{2}=5 \times 10^{-4} \mathrm{M}$ (dash). (D) Surface charge data (Pokrovsky and others, $1999 \mathrm{a}$ ) for magnesite; $(\mathbf{\square}) P_{\mathrm{CO}_{2}}=0.01 \mathrm{~atm}, \Sigma \mathrm{CO}_{2}=0.004 \mathrm{M},[\mathrm{Mg}]_{\mathrm{total}}=0.0017 \mathrm{M}$; (口) $P_{\mathrm{CO}_{2}}=0.96 \mathrm{~atm}, \Sigma \mathrm{CO}_{2}=0.0015 \mathrm{M},[\mathrm{Mg}]_{\text {total }}=0.001 \mathrm{M}$; ( $\left.\square\right) P_{\mathrm{CO}_{2}}=10^{-3.5} \mathrm{~atm}, \Sigma \mathrm{CO}_{2}=0.03 \mathrm{M}$, $[\mathrm{Mg}]_{\text {total }}=0.005 \mathrm{M} ; I=0.009-0.1 \mathrm{M},[$ magnesite $]=15.5-18.2 \mathrm{~g} \mathrm{~L}^{-1}$. Model at conditions for $(\mathbf{\square}$, thick solid line), ( $\square$, dash-dot line), and ( $\square$, dashed line) assuming equilibrium with respect to magnesite and for ( $\square$, thin solid line) assuming no equilibrium. (E) streaming potential $(\triangle)$ and electrophoresis $(\mathbf{\Delta})$ data (Pokrovsky and others, 1999c) for dolomite; $0 \leq \Sigma \mathrm{CO}_{2} \leq 0.01 \mathrm{M} ; 0 \leq[\mathrm{Me}]_{\text {total }} \leq 0.002 \mathrm{M}$; model at $\mathrm{pH}_{\mathrm{iep}}$ conditions (thick solid line; $\mathrm{pMg}=3.2, \mathrm{pCa}=3.5$ and $\Sigma \mathrm{CO}_{2}=10^{-3} \mathrm{M}$ ). (F) Surface charge data (Pokrovsky and others, 1999c) for dolomite at $P_{\mathrm{CO}_{2}}=0.96 \mathrm{~atm}$ and $I=0.5 \mathrm{NaCl}$ ( $\mathbf{\square}$, thick solid line), $I=0.01 \mathrm{NaCl}(\square)$, and $P_{\mathrm{CO}_{2}}=10^{-3.5}$ atm and $I=0.5 \mathrm{NaCl}(\diamond), I=0.1 \mathrm{NaCl}(\square), I=0.01 \mathrm{NaCl}$ $(\diamond$, thin solid line). Note the scale difference for the $\mathrm{y}$-axis compared to figure 9B and 9D. Additional model parameters: $\mathrm{C}_{1}=\mathrm{C}_{2}=100 \mathrm{~F} \mathrm{~m}^{-2}$; and as listed in tables 3-6.

5 imply a total capacitance $(\mathrm{C})$ on the order of $33 \mathrm{~F} \mathrm{~m}^{-2}$ (calculated from the relation $\Psi_{0}=\sigma / \mathrm{C}$ ), rather than $50 \mathrm{~F} \mathrm{~m}^{-2}$ as for rhodochrosite. Also, the assumption that model-derived $\Psi_{2}$ potentials coincide with experimental $\zeta$-potentials, as well as the accuracy of $\zeta$-potential determinations at low $\mathrm{pH}$, may need to be carefully reevaluated. 


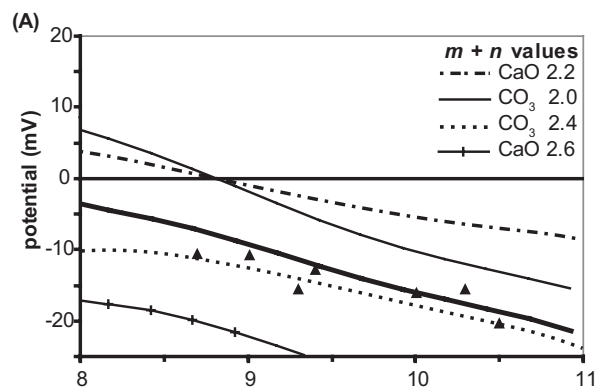

(B)

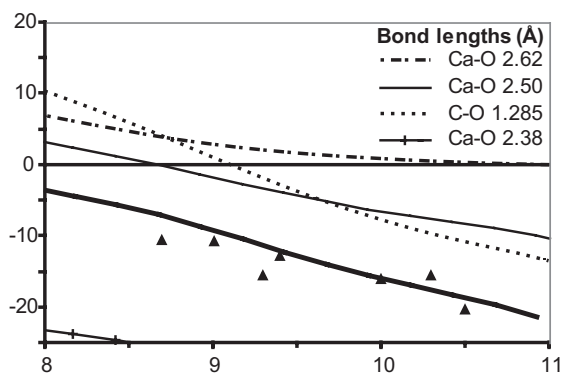

(C)

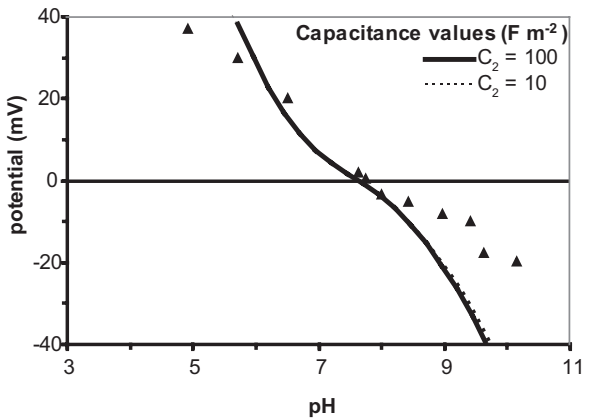

(D)

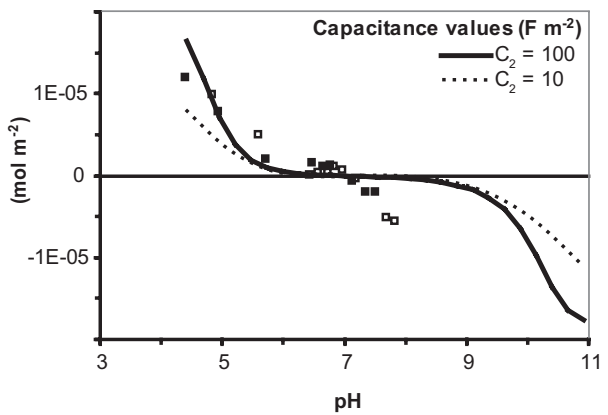

Fig. 10. Sensitivity analyses for model-predicted $\zeta$-potentials of calcite (A, B), and $\zeta$-potentials (C) plus surface charges of rhodochrosite (D). The model simulations (solid lines) consider variations in the amounts of hydrogen bridging $(m+n$, equation 2$)$ for the calcium and carbonate surface sites (A), the bond lengths $\mathrm{Ca}-\mathrm{O}$ and $\mathrm{C}-\mathrm{O}$ within the surface groups (each simulation output corresponds to the variation in one length, while keeping the other equal to the value in table 5) (B), and the capacitance $\mathrm{C}_{2}(\mathrm{C}, \mathrm{D})$. Data shown in panels $\mathrm{A}, \mathrm{B}$ are the same as in figure $5 \mathrm{~A}$, those in panel $\mathrm{C}$ as in figure $8 \mathrm{~A}$ and those in panel $\mathrm{D}$ as in figure $8 \mathrm{~B}$.

\section{Sensitivity Analyses}

The sensitivity of calculated surface potentials to a number of model assumptions and parameter values are illustrated for calcite in aqueous systems with no gas phase in figure 10. A key assumption underlying the model results shown so far is that constant numbers of hydrogen bridges to and from the surrounding water can be assigned to the surface carbonate and metal groups $(m+n=2.2$ for carbonate groups, and $m+$ $n=2.4$ for $\equiv \mathrm{CaO}$ and $\equiv \mathrm{CaOH}$ groups). Similarly, the bond lengths within the surface groups are fixed at constant values for any given carbonate mineral. In other words, the number of hydrogen bridges and the bond lengths are assumed to be independent of the structural location of the surface site, the (de)protonation of the surface group, or the composition of the background electrolyte solution. As shown by figures 10A and $10 \mathrm{~B}$, however, even small variations in the values of $m+n$ and the bond lengths of the surface groups have a major impact on the model-predicted surface potentials.

For example, varying the $\mathrm{Ca}-\mathrm{O}$ bond length by \pm 5 percent around the experimentally determined length of $2.50 \pm 0.12 \AA$ (Fenter and others, 2000) shifts the isoelectric point from $\mathrm{pH}_{\mathrm{iep}}<5$ for $\mathrm{Ca}-\mathrm{O}=2.38 \AA$ to $\mathrm{pH}_{\mathrm{iep}} \approx 11$ for $\mathrm{Ca}-\mathrm{O}=2.62 \AA$ (fig. $10 \mathrm{~B}$ ). A slightly longer $\mathrm{C}-\mathrm{O}$ bond length compared to that in the bulk calcite lattice (Effenberger and others, 1981) steepens the simulated $\mathrm{pH}$ dependence of the surface potential, and shifts $\mathrm{pH}_{\mathrm{iep}}$ to $\sim 9.2$. Molecular dynamic simulations of solvated monomers and (hydr) oxy acid surfaces have shown that the length of the C-O bond in aqueous (bi)carbonate and that of surface $\mathrm{Me}-\mathrm{O}$ bonds change in response to 
(de)protonation (Bickmore and others, 2004, 2006). In principle, such effects could be taken into account in the CD-MUSIC model, once information on bond-length changes with (de) protonation becomes available for divalent metal carbonate surfaces.

Molecular dynamics (MD) simulations carried out by Kerisit and Parker (2004) for a perfectly flat calcite mineral surface in contact with bulk water yield an average of 0.86 hydrogen bridges per surface calcium. (Note: these authors do not report the number of hydrogen bridges to the oxygen atoms of surface carbonate groups). This value is on the lower side of the range obtained from MD simulations for surface oxygens on (hydr) oxy acid surfaces (0.7-3.5, Bickmore and others 2006). Furthermore, the values of $(m+n)$ needed to fit measured surface potentials of calcite with the CD-MUSIC model are significantly higher than 0.86. In part, this discrepancy may reflect enhanced interaction of rough mineral surfaces with adsorbed water molecules compared to ideal, defect-free surfaces. Simply from a geometrical perspective, edge and corner sites should be able to accommodate more hydrogen bridges than face sites (Hiemstra and others, 1989a). The ionic strength of the solution and the protonation or deprotonation of surface sites may further affect the structure of the adsorbed water layer and, hence, the degree of hydrogen bridging.

Even among edge or corner sites the number of coordinated water molecules and bond lengths may vary. For instance, there is ample evidence for major differences in the coordination environments along acute and obtuse edges on the $\{10 \overline{1} 4\}$ face of calcite. Differences in the affinities of trace elements (for example, Paquette and Reeder, 1995; Reeder, 1996; Alexandratos and others, 2007) and small organic compounds (for example, Orme and others, 2001), as well as differences in pHdependent edge velocities during dissolution (Shiraki and others, 2000), may be related to variable amounts of coordinated water molecules and $\mathrm{Ca}-\mathrm{O}$ bond lengths between acute and obtuse edge sites. As emphasized by the results in figures $10 \mathrm{~A}$ and $10 \mathrm{~B}$, small differences in hydrogen bridging and bond lengths could be a source of uncertainty when fitting the CD-MUSIC model to experimental data.

Another assumption underlying the model simulations presented so far is that calcium and carbonate adsorb as inner-sphere complexes. To simulate outer-sphere complexation, the values of $\mathrm{B}_{0}, \mathrm{~B}_{1}$ and $\mathrm{B}_{2}$ were modified to, respectively, $-1,0$ and 2 for $\mathrm{Ca}^{2+}$ sorption, +1,0 and -1 for $\mathrm{HCO}_{3}^{-}$and $+1,0$ and -2 for $\mathrm{CO}_{3}^{2-}$. The calculated surface potentials with or without outer-sphere complexation are similar, although somewhat lower potentials are obtained for outer-sphere complexation in nonstoichiometric solutions with excess $\mathrm{Ca}^{2+}(\mathrm{aq})$ (results not shown). The potentials are also largely unaffected by variations in the capacitance values, as long as $\mathrm{C}_{1} \geq \mathrm{C}_{2}$ (fig. 10C). Calculated net surface charges, however, are more sensitive to the value chosen for $\mathrm{C}_{2}$. When $\mathrm{C}_{2}$ drops from 100 to $10 \mathrm{~F} \mathrm{~m}^{-2}$, charge build up at the surface decreases somewhat, but the isoelectric point remains unaffected (fig. 10D).

CONCLUSIONS

The electrochemical properties of divalent metal carbonate minerals are far more challenging to model than those of metal oxide minerals. This reflects not only the experimental difficulties associated with the acquisition and interpretation of electrokinetic measurements and surface titration data, but also the inherently more complex surface chemistry of carbonate minerals. The very different proton affinities of carbonate and metal surface groups, as well as the more pronounced role of adsorption of the mineral constituents ions, results in a much broader spectrum of responses of the surface speciation and net electrical charge to changes in experimental conditions. For example, the isoelectric point of calcite varies widely, with reported values ranging from less than 7 to more than 11. A comparative analysis of model simulations and data reveals that the highly variable $\mathrm{pH}$ trends of the surface potential of calcite and other divalent metal carbonates may result from relatively minor 
differences in equilibration times, solution stoichiometry, and the purity plus roughness of the particle surfaces.

Compared to the existing SCM, the CD-MUSIC approach offers a more realistic representation of the carbonate-aqueous solution interface, which allows one to compute surface potentials of carbonate minerals. As a result, surface potential measurements can be used to test the performance of the surface chemical model. Further progress, however, will depend on the acquisition of consistent data sets. Our recommendations for experimental studies are to (i) use well-characterized and properly washed mineral surfaces, (ii) combine surface charge and electrokinetic measurements on the same mineral surfaces, (iii) perform experiments in closed systems (with no gas phase) or, when using open systems, insure that equilibrium between the solution and $\mathrm{CO}_{2}(\mathrm{~g})$ is reached, (iii) determine the in situ solution and gas compositions, that is, at the moment the surface charge or surface potential is measured, and (iv) in addition to $\mathrm{pH}$ titrations also titrate the mineral suspensions with the (potential-determining) mineral constituent ions. Finally, we strongly believe that a combination of experimental measurements and modeling may offer the most suitable approach to build a mechanistic understanding of the surface chemistry of carbonate minerals.

The representation of the chemical structure of the carbonate mineral-aqueous solution interface in the CD-MUSIC model could be improved by allowing the bond lengths and the number of hydrogen bridges to vary among structurally different surface sites. In the simulations presented here, all sites are assigned the same, average values of these model parameters. While this is a reasonable approximation given the present state of knowledge, simulations indicate that model-predicted surface charges and potentials are highly sensitive to distortion of the surface lattice (relaxation) and hydrogen bridging with adsorbed water molecules. Further research is needed, however, to determine how the bond lengths and number of hydrogen bridges vary from site to site, and how they respond to changes in solution composition. Molecular dynamic simulations of the carbonate mineral-water interface represent one promising approach to obtain this information.

ACKNOWLEDGMENTS

This research was funded by VENI grant \#016.071.018 of the Netherlands Organization for Research (NWO) to MW, an NWO Pioneer grant to PVC, and by the French National Radioactive Waste Management Agency (ANDRA) to MW and LC. We would like to acknowledge the insightful reviews of O. Pokrovsky, J. Kubicki and two anonymous reviewers.

\section{REFERENCES}

Amankonah, J. O., and Somasundaran, P., 1985, Effects of dissolved mineral species on the electrokinetic behavior of calcite and apatite: Colloids and Surfaces, v. 15, p. 335-353, doi:10.1016/0166$6622(85) 80082-2$

Alexandratos, V. G., Elzinga, E. J., and Reeder, R. J., 2007, Arsenate uptake by calcite: Macroscopic and spectroscopic characterization of adsorption and incorporation mechanisms: Geochimica et Cosmochimica Acta, v. 71, p. 4172-4187, doi:10.1016/j.gca.2007.06.055.

Arakaki, T., and Mucci, A., 1995, A continuous and mechanistic representation of calcite reaction-controlled kinetics in dilute solutions at $25^{\circ} \mathrm{C}$ and $1 \mathrm{Atm}$ total pressure: Aquatic Geochemistry, v. 1, p. 105-130, doi:10.1007/BF01025233.

Archer, D., and Maier-Reimer, E., 1994, Effect of deep-sea sedimentary calcite preservation on atmospheric $\mathrm{CO}_{2}$ concentration: Nature, v. 367, p. 260-263, doi:10.1038/367260a0.

Arvidson, R. S., Collier, M., Davis, K. J., Vinson, M. D., Amonette, J. E., and Lüttge, A., 2006, Magnesium inhibition of calcite dissolution kinetics: Geochimica et Cosmochimica Acta, v. 70, p. 583-594, doi:10.1016/j.gca.2005.10.005.

Bargar, J. R., Towle, S. N., Brown, G. E., Jr., and Parks, G. A., 1997, XAFS and Bond-Valence Determination of the Structures and Compositions of Surface Functional Groups and $\mathrm{Pb}(\mathrm{II})$ and $\mathrm{Co}(\mathrm{II})$ Sorption Products on Single-Crystal $\alpha-\mathrm{Al}_{2} \mathrm{O}_{3}$ : Journal of Colloid and Interface Science, v. 185, p. 473-492, doi:10.1006/jcis.1996.4574. 
Bickmore, B. R., Tadanier, C. J., Rosso, K. M., Monn, W. D., and Eggett, D. L., 2004, Bond-valence methods for pKa prediction: Critical reanalysis and a new approach: Geochimica et Cosmochimica Acta, v. 68, p. 2025-2042, doi:10.1016/j.gca.2003.11.008.

Bickmore, B. R., Rosso, K. M., Tadanier, C. J., Bylaska, E. J., and Doud, D., 2006, Bond-valence methods for $\mathrm{pKa}$ prediction. II. Bond-valence, electrostatic, molecular geometry, and solvation effects: Geochimica et Cosmochimica Acta, v. 70, p. 4057-4071, doi:10.1016/j.gca.2006.06.006.

Bockris, J. J'O., and Khan, S. U. M., 1993, Surface Electrochemistry: A Molecular Level Approach: New York, Plenum Press, 1014 p.

Brady, P. V., Krumhansl, J. L., and Papenguth, H. W., 1996, Surface complexation clues to dolomite growth: Geochimica et Cosmochimica Acta, v. 60, p. 727-731, doi:10.1016/0016-7037(95)00436-X.

Brown, I. D., and Altermatt, D., 1985, Bond-valance parameters obtained from a systematic analysis of the inorganic crystal structure database: Acta Crystallographica, v. B41, p. 244-247, doi: 10.1107/ S0108768185002063.

Charlet, L., Wersin, P., and Stumm, W., 1990, Surface charge of $\mathrm{MnCO}_{3}$ and $\mathrm{FeCO}_{3}$ : Geochimica et Cosmochimica Acta, v. 54, p. 2329-2336, doi:10.1016/0016-7037(90)90059-T.

Chen, G., and Tao, D., 2004, Effect of solution chemistry on floatability of magnesite and dolomite: International Journal of Mineral Processing, v. 74, p. 343-357, doi:10.1016/j.minpro.2004.04.004.

Chiarello, R. P., and Sturchio, N. C., 1995, The calcite (1014) cleavage surface in water: Early results of a crystal truncation rod study: Geochimica et Cosmochimica Acta, v. 59, p. 4557-4561, doi:10.1016/00167037(95)00363-5.

Chiarello, R. P., Wogelius, R. A., and Sturchio, N. C., 1993, In-situ synchrotron X-ray reflectivity measurements at the calcite-water interface: Geochimica et Cosmochimica Acta, v. 57, p. 4103-4110.

Chibowski, E., Szczes, A., and Holysz, L., 2005, Influence of Sodium Dodecyl Sulfate and Static Magnetic Field on the Properties of Freshly Precipitated Calcium Carbonate: Langmuir, v. 21, p. 8114-8122, doi: $10.1021 / \mathrm{la} 050575 f$.

Chou, L., Garrels, R. M., and Wollast, R., 1989, Comparative study of the kinetics and mechanisms of dissolution of carbonate minerals: Chemical Geology, v. 78, p. 269-282, doi:10.1016/0009$2541(89) 90063-6$.

Cicerone, D. S., Regazzoni, A. E., and Blesa, M. A., 1992, Electrokinetic Properties of the Calcite/Water Interface in the Presence of Magnesium and Organic Matter: Journal of Colloid and Interface Science, v. 154, p. 423-433, doi:10.1016/0021-9797(92)90158-I.

Cygan, R. T., Wright, K., Fisler, D. K., Gale, J. D., and Slater, B., 2002, Atomistic models of carbonate minerals: bulk and surface structures, defects, and diffusion: Molecular Simulation, v. 28, p. 475-495, doi:10.1080/08927020290030099.

Davis, J. A., and Kent, D. B., 1990, Surface complexation modeling in aqueous geochemistry, in Hochella, M. F., and White, A. F., editors, Mineral-water interface geochemistry: Reviews in Mineralogy, v. 23, p. $177-260$.

Davis, J. A., James, R. O., and Leckie, J. O., 1978, Surface Ionization and Complexation at the Oxide/Water Interface, I. Computation of Electrical Double Layer Properties in Simple Electrolytes: Journal of Colloid and Interface Science, v. 63, p. 480-499, doi:10.1016/S0021-9797(78)80009-5.

Davis, K. J., Dove, P. M., and De Yoreo, J. J., 2000, The Role of Mg2+ as an Impurity in Calcite Growth: Science, v. 290, p. 1134-1137, doi:10.1126/science.290.5494.1134.

De Giudici, G., 2002, Surface control vs. diffusion control during calcite dissolution: Dependence of step-edge velocity upon solution pH: American Mineralogist, v. 87, p. 1279-1285.

De Leeuw, N. H., and Parker, S. C., 1997, Atomistic simulation of the effect of molecular adsorption of water on the surface structure and energies of calcite surfaces: Journal of the Chemical Society - Faraday Transactions, v. 93, p. 467-475, doi: 10.1039/a606573b.

— 1998, Surface structure and morphology of calcium carbonate polymorphs calcite, aragonite, and vaterite: An atomistic approach: Journal of Physical Chemistry B, v. 102, p. 2914-2922, doi: 10.1021/ jp973210f.

Douglas, H. W., and Walker, R. A., 1950, The electrokinetic behaviour of Iceland Spar against aqueous electrolyte solutions: Transactions of the Faraday Society, v. 46, p. 559-568, doi: 10.1039/ TF9504600559.

Dove, P. M., and Hochella, M. F., Jr., 1993, Calcite precipitation mechanisms and inhibition by orthophosphate: In situ observations by Scanning Force Microscopy: Geochimica et Cosmochimica Acta, v. 57, p. 705-714, doi:10.1016/0016-7037(93)90381-6.

Duckworth, O. W., and Martin, S. T., 2003, Connections between surface complexation and geometric models of mineral dissolution investigated for rhodochrosite: Geochimica et Cosmochimica Acta, v. 67, p. 1787-1801, doi:10.1016/S0016-7037(02)01305-4.

2004, Dissolution rates and pit morphologies of rhombohedral carbonate minerals: American Mineralogist, v. 89, p. 554-563.

Effenberger, H., Mereiter, K., and Zemann, J., 1981, Crystal structure refinements of magnesite, calcite, rhodochrosite, siderite, smithsonite, and dolomite, with the discussion of some aspects of the stereochemistry of Calcite type carbonates: Zeitschfrift für Kristallographie, v. 156, p. 233-243.

Eriksson, R., Merta, J., and Rosenholm, J. B., 2007, The calcite/water interface. I. Surface charge in indifferent electrolyte media and the influence of low-molecular-weight polyelectrolyte: Journal of Colloid and Interface Science, v. 313, p. 184-193, doi:10.1016/j.jcis.2007.04.034.

Fenter, P., and Sturchio, N. C., 2005, Mineral-water interfacial structures revealed by synchrotron X-ray scattering: Progress in Surface Science, v. 77, p. 171-258, doi:10.1016/j.progsurf.2004.12.001.

Fenter, P., Geissbühler, P., DiMasi, E., Srajer, G., Sorensen, L. B., and Sturchio, N. C., 2000, Surface speciation of calcite observed in situ by high-resolution X-ray reflectivity: Geochimica et Cosmochimica Acta, v. 64, p. 1221-1228, doi:10.1016/S0016-7037(99)00403-2. 
Foxall, T., Peterson, G. C., Rendall, H. M., and Smith A. L., 1979, Charge determination at calcium salt/aqueous solution interface: Journal of the Chemical Society, Faraday Transactions 1, v. 75, p. 1034-1039, doi: 10.1039/F19797501034.

Fuerstenau, D. W., Pradip and Herrera-Urbina, R., 1992, The surface chemistry of bastnaesite, barite and calcite in aqueous carbonate solutions: Colloids and Surfaces, v. 68, p. 95-102.

Geissbühler, P., Fenter, P., DiMasi, E., Srajer, G., Sorensen, L. B., and Sturchio, N. C., 2004, Threedimensional structure of the calcite-water interface by surface X-ray scattering: Surface Science, v. 573, p. 191-203, doi:10.1016/j.susc.2004.09.036.

Gratz, A. J., Hillner, P. E., and Hansma, P. K., 1993, Step dynamics and spiral growth on calcite: Geochimica et Cosmochimica Acta, v. 57, p. 491-495, doi:10.1016/0016-7037(93)90449-7.

Gruzensky, P. M., 1967, Growth of calcite crystals, in Peiser, H. S., editor, Crystal Growth: Oxford, Pergamon Press, p. 365-367.

Hanumantha Rao, K., Antti, B.-M., and Forssberg, E., 1989, Mechanism of oleate interaction on salt-type minerals: Part I. Adsorption and Electrokinetic Studies of Calcite in the Presence of sodium Oleate and Sodium Metasilicate: Colloids and Surfaces, v. 34, p. 227-239, doi:10.1016/0166-6622(88)80101-X.

Hayes, K. F., and Leckie J. O., 1987, Modelling Ionic Strength Effects on Cation Adsorption at Hydrous Oxide/Solution Interfaces: Journal of Colloid and Interface Science, v. 115, p. 564-572, doi:10.1016/ 0021-9797(87)90078-6.

Hiemstra, T., and Van Riemsdijk, W. H., 1996, A Surface Structural Approach to Ion Adsorption: The Charge Distribution (CD) Model: Journal of Colloid and Interface Science, v. 179, p. 488-508, doi:10.1006/ jcis.1996.0242.

2006, On the relationship between charge distribution, surface hydration, and the structure of the interface of metal hydroxides: Journal of Colloid and Interface Science, v. 301, p. 1-18.

Hiemstra, T., Van Riemsdijk, W. H., and Bolt, G. H., 1989a, Multisite proton adsorption modeling at the solid/solution interface of (Hydr) oxides: A new approach. I. Model description and evaluation of intrinsic reaction constants: Journal of Colloid and Interface Science, v. 133, p. 91-104, doi:10.1016/ 0021-9797(89)90284-1.

Hiemstra, T., De Wit, J. C. M., and Van Riemsdijk, W. H., 1989b, Multisite proton adsorption modeling at the solid/solution interface of (Hydr) oxides: a new approach. II Application to various important (Hydr)oxides: Journal of Colloid and Interface Science, v. 133, p. 105-117, doi:10.1016/0021-9797(89)90285-3.

Hiemstra, T., Venema, P., and Van Riemsdijk, W. H., 1996, Intrinsic Proton Affinity of Reactive Surface Groups of Metal (Hydr) oxides: The Bond Valence Principle: Journal of Colloid and Interface Science, v. 184 , p. $680-692$, doi:10.1006/jcis.1996.0666.

Higgins, S. R., Jordan, G., and Eggleston, C. M., 2002, Dissolution kinetics of magnesite in acidic aqueous solution: A hydrothermal atomic force microscopy study assessing step kinetics and dissolution flux: Geochimica et Cosmochimica Acta, v. 66, p. 3201-3210.

Hillner, P. E., Gratz, A. J., Manne, S., and Hansma, P. K., 1992, Atomic-scale imaging of calcite growth and dissolution in real time: Geology, v. 20, p. 359-362.

Huang, Y. C., Fowkes, F. M., Lloyd, T. B., and Sanders, N. D., 1991, Adsorption of calcium ions from calcium chloride solutions onto calcium carbonate particles: Langmuir, v. 7, p. 1742-1748, doi: 10.1021/ la00056a028.

Jahnke, R. A., and Jahnke, D. B., 2004, Calcium carbonate dissolution in deep sea sediments: Reconciling microelectrode, pore water and benthic flux chamber results: Geochimica et Cosmochimica Acta, v. 68, p. 47-59, doi:10.1016/S0016-7037(03)00260-6.

Jordan, G., and Rammensee, W., 1998, Dissolution rates of calcite (10 $\overline{1} 4$ ) obtained by scanning force microscopy: Microtopography-based dissolution kinetics on surfaces with anisotropic step velocities: Geochimica et Cosmochimica Acta, v. 62, p. 941-947, doi:10.1016/S0016-7037(98)00030-1.

Keizer, M. G., and van Riemsdijk, W. H., 2002, ECOSAT: Department of Soil Science and Plant Nutrition, Wageningen Agricultural University, Wageningen, The Netherlands.

Kerisit, S., and Parker, S. C., 2004, Free energy of adsorption of water and calcium on the $\{10 \overline{1} 4\}$ calcite surface: Chemical Communications, v. 10, p. 52-53, doi:10.1039/b311928a.

Kerisit, S., Parker, S. C., and Harding, J. H., 2003, Atomistic simulation of the dissociative adsorption of water on calcite surfaces: Journal of Physical Chemistry B, v. 107, p. 7676-7682, doi:10.1021/jp034201b.

Klein, C., and Hurlbut, C. S., 1985, Manual of Mineralogy: New York, Wiley and Sons, 596 p.

Koretsky, C. M., Sverjensky, D. A., and Sahai, N., 1998, A model of surface site types on oxide and silicate minerals based on crystal chemistry: implications for site types and densities, multi-site adsorption, surface infrared spectroscopy, and dissolution kinetics: American Journal of Science, v. 298, p. 349-438.

Lasaga, A. C., and Lüttge, A., 2001, Variation of crystal dissolution rate based on a dissolution stepwave model: Science, v. 291, p. 2400-2404, doi:10.1126/science.1058173.

2003, A model for crystal dissolution: European Journal of Mineralogy, v. 15, p. 603-615, doi:10.1127/ 0935-1221/2003/0015-0603

Lea, A. S., Amonette, J. E., Baer, D. R., Liang, Y., and Colton, N. G., 2001, Microscopic effects of carbonate, manganese, and strontium ions on calcite dissolution: Geochimica et Cosmochimica Acta, v. 65, p. 369-379, doi:10.1016/S0016-7037(00)00531-7.

Liang, Y., and Baer, D. R., 1997, Anisotropic dissolution at the $\mathrm{CaCO}_{3}(10 \overline{1} 4)$-water interface: Surface Science, v. 373, p. 275-287, doi:10.1016/S0039-6028(96)01155-7.

Liang, Y., Lea, A. S., Baer, D. R., and Engelhard, M. H., 1996, Structure of the cleaved $\mathrm{CaCO}_{3}(10 \overline{1} 4)$ surface in an aqueous environment: Surface Science, v. 351, p. 172-182, doi:10.1016/0039-6028(95)01298-2.

Lüttge, A., Winkler, U., and Lasaga, A. C., 2003, Interferometric study of the dolomite dissolution: A new conceptual model for mineral dissolution: Geochimica et Cosmochimica Acta, v. 67, p. 1099-1116, doi:10.1016/S0016-7037(02)00914-6. 
Macinnis, I. N., and Brantley, S. L., 1992, The role of dislocations and surface morphology in calcite dissolution: Geochimica et Cosmochimica Acta, v. 56, p. 1113-1126, doi:10.1016/0016-7037(92)90049-O.

Mackenzie, F. T., 2003, Carbonate mineralogy and geochemistry, in Middleton, G. V., editor, Encyclopedia of sediments and sedimentary rocks: Boston, Kluwer Academic Publishers, p. 93-100.

Mao, Y., and Siders, P. D., 1997, Molecular Hartree-Fock model of calcium carbonate: Journal of Molecular Structure (THEOCHEM), v. 419, p. 173-184, doi:10.1016/S0166-1280(97)00186-3.

Markgraf, S. A., and Reeder, R. J., 1985, High-temperature structure refinements of calcite and magnesite: American Mineralogist, v. 70, p. 590-600.

Martin-Garin, A., Van Cappellen, P., and Charlet, L., 2003, Aqueous cadmium uptake by calcite: A stirred flow-through reactor study: Geochimica et Cosmochimica Acta, v. 67, p. 2763-2774, doi:10.1016/S00167037(03)00091-7.

Mishra, S. K., 1978, The electrokinetics of apatite and calcite in inorganic electrolyte environment: International Journal of Mineral Processing, v. 5, p. 69-83, doi:10.1016/0301-7516(78)90006-6.

Morse, J. W., and Arvidson, R. S., 2002, The dissolution kinetics of major sedimentary carbonate minerals: Earth-Science Reviews, v. 58, p. 51-84, doi:10.1016/S0012-8252(01)00083-6.

Morse, J. W., and Mackenzie, F. T., 1990, Geochemistry of sedimentary carbonates: Amsterdam, The Netherlands, Elsevier, Developments in Sedimentology, v. 48, 696 p.

Morse, J. W., Andersson, A. J., and Mackenzie, F. T., 2006, Initial responses of carbonate-rich shelf sediments to rising atmospheric $p \mathrm{CO}_{2}$ and "ocean acidification": Role of high Mg-calcites: Geochimica et Cosmochimica Acta, v. 70, p. 5814-5830, doi:10.1016/j.gca.2006.08.017.

Morse, J. W., Arvidson, R. S., and Lüttge, A., 2007, Calcium carbonate formation and dissolution: Chemical Reviews, v. 107, p. 342-381, doi:10.1021/cr050358j.

Moulin, P., and Roques, H., 2003, Zeta potential measurement of calcium carbonate: Journal of Colloid and Interface Science, v. 261, p. 115-126, doi:10.1016/S0021-9797(03)00057-2.

Na, C., Kendall, T. A., and Martin, S. T., 2007, Surface-Potential Heterogeneity of Reacted Calcite and Rhodochrosite: Environmental Science and Technology, v. 41, p. 6491-6497, doi:10.1021/es070979p.

Ohnesorge, F., and Binnig, G., 1993, True atomic resolution by atomic force microscopy through repulsive and attractive forces: Science, v. 260, p. 1451-1456, doi:10.1126/science.260.5113.1451.

Orme, C. A., Noy, A., Wierzbicki, A., McBride, M. T., Grantham, M., Teng, H. H., Dove, P. M., and DeYoreo, J. J., 2001, Formation of chiral morphologies through selective binding of amino acids to calcite surface steps: Nature, v. 411, p. 775-779, doi:10.1038/35081034.

Ozcan, O., and Bulutcu, A. N., 1993, Electrokinetic, infrared and flotation studies of scheelite and calcite with oxine, alkyl oxine, oleoyl sarcosine and quebracho: International Journal of Mineral Processing, v. 39, p. 275-290, doi:10.1016/0301-7516(93)90020-B.

Paquette, J., and Reeder, R. J., 1995, Relationship between surface structure, growth mechanism, and trace element incorporation in calcite: Geochimica et Cosmochimica Acta, v. 59, p. 735-749, doi:10.1016/ 0016-7037(95)00004-J.

Patil, M. R., Shivakumar, K. S., Prakash, S., and Rao, R. B., 1998, Effect of Organic Reagents on the Zeta Potentials of Graphite, Quartz and Calcite Minerals: Journal of Surface Science and Technology, v. 14, p. 280-285.

Pierre, A., Lamarche, J. M., Mercier, R., Foissy, A., and Persello, J., 1990, Calcium as Potential Determining Ion in Aqueous Calcite Suspensions: Journal of Dispersion Science and Technology, v. 11, p. 611-635, doi:10.1080/01932699008943286.

Plummer, L. N., and Busenberg, E., 1982, The solubilities of calcite, aragonite and vaterite in $\mathrm{CO}_{2}-\mathrm{H}_{2} \mathrm{O}$ solutions between 0 and $90^{\circ} \mathrm{C}$, and an evaluation of the aqueous model for the system $\mathrm{CaCO}_{3}-\mathrm{CO}_{2}$ $\mathrm{H}_{2} \mathrm{O}$ : Geochimica et Cosmochimica Acta, v. 46, p. 1011-1040, doi:10.1016/0016-7037(82)90056-4.

Plummer, L. N., Wigley, T. M. L., and Parkhurst, D. L., 1978, The Kinetics of calcite dissolution in $\mathrm{CO}_{2}$-water systems at $5^{\circ}$ to $60^{\circ} \mathrm{C}$ and 0.0 to $1.0 \mathrm{~atm} \mathrm{CO}_{2}$ : American Journal of Science, v. 278, p. 179-216.

Pokrovsky, O. S., and Schott, J., 1999, Processes at the magnesium-bearing carbonates/solution interface. II. Kinetics and mechanism of magnesite dissolution: Geochimica et Cosmochimica Acta, v. 63, p. 881-897, doi:10.1016/S0016-7037(99)00013-7.

2002, Surface chemistry and dissolution kinetics of divalent metal carbonates: Environmental Science and Technology, v. 36, p. 426-432, doi:10.1021/es010925u.

Pokrovsky, O. S., Schott, J., and Thomas, F., 1999a, Processes at the magnesium-bearing carbonates/solution interface. I. a surface speciation model for magnesite: Geochimica et Cosmochimica Acta, v. 63, p. 863-880, doi:10.1016/S0016-7037(99)00008-3.

1999b, Dolomite surface speciation and reactivity in aquatic systems: Geochimica et Cosmochimica Acta, v. 63, p. 3133-3143, doi:10.1016/S0016-7037(99)00240-9.

Pokrovsky, O. S., Mielczarski, J. A., Barres, O., and Schott, J., 2000, Surface speciation models of calcite and dolomite/aqueous solution interfaces and their spectroscopic evaluation: Langmuir, v. 16, p. 26772688, doi:10.1021/la980905e.

Prédali, J. J., and Cases, J. M., 1973, Zeta potential of magnesian carbonates in inorganic electrolytes: Journal of Colloid and Interface Science, v. 45, p. 449-458, doi:10.1016/0021-9797(73)90160-4.

Pugh, R., and Stenius, P., 1985, Solution chemistry studies and flotation behaviour of apatite, calcite and fluorite minerals with sodium oleate collector: International Journal of Mineral Processing, v. 15, p. 193-218, doi:10.1016/0301-7516(85)90035-3.

Rachlin, A. L., Henderson, G. S., and Goh, M. C., 1992, An atomic force microscope (AFM) study of the calcite cleavage plane; image averaging in Fourier space: American Mineralogist, v. 77, p. 904-910.

Reeder, R. J., 1996, Interaction of divalent cobalt, zinc, cadmium, and barium with the calcite surface during layer growth: Geochimica et Cosmochimica Acta, v. 60, p. 1543-1552, doi:10.1016/0016-7037(96)00034-8.

Rickard, D., and Sjōberg, E. L., 1983, Mixed kinetic control of calcite dissolution rates: American Journal of Science, v. 283, p. 815-830. 
Rimstidt, J. D., Balog, A., and Webb, J., 1998, Distribution of trace elements between carbonate minerals and aqueous solutions: Geochimica et Cosmochimica Acta, v. 62, p. 1851-1863, doi:10.1016/S00167037(98)00125-2.

Rodríguez, K., and Araujo, M., 2006, Temperature and pressure effects on zeta potential values of reservoir minerals: Journal of Colloid and Interface Science, v. 300, p. 788-794, doi:10.1016/j.jcis.2006.04.030.

Rohl, A. L., Wright, K., and Gale, J. D., 2003, Evidence from surface phonons for the (2x1) reconstruction of the (1014) surface of calcite from computer simulation: American Mineralogist, v. 88, p. 921-925.

Sampat Kumar, V. Y., Mohan, N., and Biswas, A. K., 1971, Fundamental studies on the role of carbon dioxide in a calcite flotation system: Transactions of the Society of Mining Engineers, v. 250, p. 182-186.

Schindler, P. W., and Stumm, W., 1987, The surface chemistry of oxides, hydroxides, and oxide minerals, in Stumm, W., editor, Aquatic Surface Chemistry: New York, Wiley and Sons, p. 83-110.

Schott, J., Brantley, S., Crerar, D., Guy, C., Borcsik, M., and Willaime, C., 1989, Dissolution kinetics of strained calcite: Geochimica et Cosmochimica Acta, v. 53, p. 373-382, doi:10.1016/00167037(89)90389-X.

Shiraki, R., Rock, P. A., and Casey, W. H., 2000, Dissolution kinetics of calcite in $0.1 \mathrm{M} \mathrm{NaCl}$ solution at room temperature: An atomic force microscopic (AFM) study: Aquatic Geochemistry, v. 6, p. 87-108, doi:10.1023/A:1009656318574.

Siffert, B., and Fimbel, P., 1984, Parameters affecting the sign and the magnitude of the electrokinetic potential of calcite: Colloids and Surfaces, v. 11, p. 377-389, doi:10.1016/0166-6622(84)80074-8.

Smani, M. S., Blazy, P., and Cases, J. M., 1975, Beneficiation of sedimentary Moroccan phosphate ores: Transactions of the Society of Mining Engineers, v. 258, p. 168-182.

Somasundaran, P., and Agar, G. E., 1967, The zero point of charge of calcite: Journal of Colloid and Interface Science, v. 24, p. 433-440, doi:10.1016/0021-9797(67)90241-X.

Somasundaran, P., Deo, N., Deo, P., and Natarajan, K. A., 2005, Role of biopolymers on bacterial adhesion and mineral beneficiation: Minerals and Metallurgical Processing, v. 22, p. 1-11.

Sposito, G., 1984, The surface chemistry of soils: New York, Oxford University Press, 234 p.

Stern, O. Z., 1924, Zur Theorie der elektrolytischen Doppelschicht: Zeitschrift für Elektrochemie, v. 30, p. $508-516$.

Stipp, S. L., and Hochella, M. F., Jr., 1991, Structure and bonding environments at the calcite surface as observed with X-ray photoelectron spectroscopy (XPS) and low energy electron diffraction (LEED): Geochimica et Cosmochimica Acta, v. 55, p. 1723-1736, doi:10.1016/0016-7037(91)90142-R.

Stipp, S. L. S., Eggleston, C. M., and Nielsen, B. S., 1994, Calcite surface structure observed at microtopographic and molecular scales with atomic force microscopy (AFM): Geochimica et Cosmochimica Acta, v. 58, p. 3023-3033, doi:10.1016/0016-7037(94)90176-7.

Stipp, S. L. S., Gutmannsbauer, W., and Lehmann, T., 1996, The dynamic nature of calcite surfaces in air: American Mineralogist, v. 81, p. 1-8.

Sverjensky, D. A., 2005, Prediction of surface charge on oxides in salt solutions: Revisions for 1:1 ( $\left.\mathrm{M}^{+} \mathrm{L}^{-}\right)$ electrolytes: Geochimica et Cosmochimica Acta, v. 69, p. 225-257, doi:10.1016/j.gca.2004.05.040.

Teng, H. H., Dove, P. M., and DeYoreo, J. J., 1999, Reversed calcite morphologies induced by microscopic growth kinetics: Insight into biomineralization: Geochimica et Cosmochimica Acta, v. 63, p. 2507-2512, doi:10.1016/S0016-7037(99)00103-9.

- 2000, Kinetics of calcite growth: surface processes and relationships to macroscopic rate laws: Geochimica et Cosmochimica Acta, v. 64, p. 2255-2266, doi:10.1016/S0016-7037(00)00341-0.

Thompson, D. W., and Pownall, P. G., 1989, Surface electrical properties of calcite: Journal of Colloid and Interface Science, v. 131, p. 74-82.

Titiloye, J. O., de Leeuw, N. H., and Parker, S. C., 1998, Atomistic simulation of the differences between calcite and dolomite surfaces: Geochimica et Cosmochimica Acta, v. 62, p. 2637-2641, doi:10.1016/S00167037(98)00177-X.

Tournassat, C., Ferrage, E., Poinsignon, C., and Charlet, L., 2004, The titration of clay minerals: II. Structure-based model and implications for clay reactivity: Journal of Colloid and Interface Science, v. 273, p. 234-246, doi:10.1016/j.jcis.2003.11.022.

Van Cappellen, P., Charlet, L., Stumm, W., and Wersin, P., 1993, A surface complexation model of the carbonate mineral-aqueous solution interface: Geochimica et Cosmochimica Acta, v. 57, p. 3505-3518, doi:10.1016/0016-7037(93)90135-J.

Vdović, N., and Bišćan, J., 1998, Electrokinetics of natural and synthetic calcite suspensions: Colloids and Surfaces A: Physicochemical and Engineering Aspects, v. 137, p. 7-14, doi:10.1016/S09277757(97)00179-9.

Wersin, P., Charlet, L., Karthein, R., and Stumm, W., 1989, From adsorption to precipitation: Sorption of $\mathrm{Mn}^{2+}$ on $\mathrm{FeCO}_{3}(\mathrm{~s})$ : Geochimica et Cosmochimica Acta, v. 53, p. 2787-2796, doi:10.1016/00167037(89) $90156-7$.

Westall, J. C., 1986, Reactions at the oxide-solution interface: Chemical and electrostatic models, in Davis, J. A., and Hayes, K. F., editors, Geochemical processes at mineral surfaces: American Chemical Society Symposium Series, v. 323, p. 54-78.

Wray, J. L., and Daniels, F., 1957, Precipitation of calcite and aragonite: Journal of the American Chemical Society, v. 79, p. 2031-2034, doi: 10.1021/ja01566a001.

Wright, K., Cygan, R. T., and Slater, B., 2001, Structure of the (101̄4) surfaces of calcite, dolomite and magnesite under wet and dry conditions: Physical Chemistry Chemical Physics, v. 3, p. 839-844, doi:10.1039/b0061301.

2002, Impurities and nonstoichiometry in the bulk and on the (1014) surface of dolomite: Geochimica et Cosmochimica Acta, v. 66, p. 2541-2546, doi:10.1016/S0016-7037(02)00846-3. 
Yarar, B., and Kitchener, J. A., 1970, Selective flocculation of minerals. 1-Basic principles, 2- experimental investigation of quartz, calcite and galena: Transactions of the Institution of Mining and Metallurgy, Section C: Mineral Processing and Extractive Metallurgy, v. 79, p. 23-33.

Yates, D. E., Levine, S., and Healy, T. W., 1974, Site-binding model of the electrical double laver at the oxide/water interface: Journal of the Chemical Society - Faraday Transactions I, v. 70, p. 1807-1818, doi: $10.1039 /$ F19747001807.

Yuehua, H., Lin, L., and Guangzhou, Q., 1995, Solution chemistry of electrokinetic behaviour of carbonate minerals: Transactions of Nonferrous Metals Society of China, v. 5, p. 26-30. 